\title{
MITIGATING THE CLASSROOM EFFECTS OF IMPLICIT BIAS ON MINORITY STUDENT ACHIEVEMENT
}

\author{
A Dissertation submitted to the faculty of \\ San Francisco State University \\ In partial fulfillment of \\ the requirements for \\ the Degree
}

Doctor of Education

In

Educational Leadership

by

Silindra Nicole McRay

San Francisco, California

May 2020 
Copyright by

Silindra Nicole McRay

2020 


\section{CERTIFICATION OF APPROVAL}

I certify that I have read Mitigating the classroom Effects of Implicit Bias on Minority Student Achievement by Silindra Nicole McRay, and that in my opinion this work meets the criteria for approving a thesis submitted in partial fulfillment of the requirement for the degree Doctor of Education in Educational Leadership at San Francisco State University.

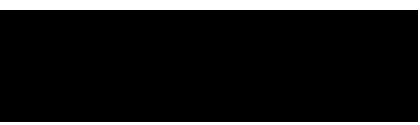

Stephanie Sisk-Hilton, Ph.D.

Professor and Interim Chair

Department of Elementary Education

San Francisco State University

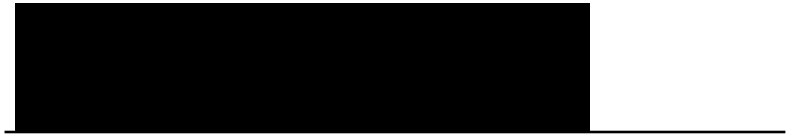

Janine Saunders, Ed.D.

Adjunct Faculty

San Francisco State University

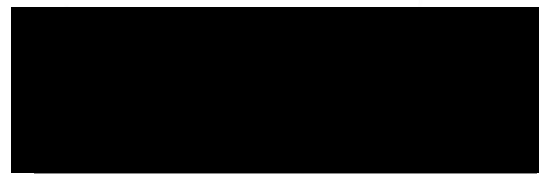

Kyla Johnson-Trammell, Ed.D.

Superintendent

Oakland Unified School District 


\title{
MITIGATING THE CLASSROOM EFFECTS OF IMPLICIT BIAS ON MINORITY STUDENT ACHIEVEMENT
}

\author{
Silindra Nicole McRay \\ San Francisco, California
}

2020

While the curriculum itself is one form of bias, individual instructors play a significant role in how students experience the classroom space. Therefore, this in-depth study involved co-research with three teachers who were exploring the role of implicit bias in their own teaching practice. I engaged these teachers in the critical self-reflection of their teaching practice, by engaging in a process of reflecting on their practice through the lens of identifying potential bias, using a pilot version of a tool developed for this purpose (Equip). Through this method, teachers were led through a series of discussions and prompts that helped them to look introspectively into how their teaching might influence student outcomes. As such, the research question asked: What are the impacts of a reflective tool intended to support teachers to notice and address implicit bias in their teaching practice? The Implicit Bias Reflection Tool (IBRT) was then developed based on analysis of initial data from interviews with teachers using an existing video observational tool, Equip. Based on the outcomes of their initial self-reflection, and with the use of literature around this topic, I created the IBRT, aimed at helping them keep their biases at the forefront of instruction and student interactions, with the hope of helping them to become more conscientious of how these interactions can affect student outcomes. I then tested the tool that I developed, in hopes that their input would help me to refine and redefine what it means to be an effective teacher, conscious of their implicit biases. The findings of this study show promise in the IBRT's ability to create the space that teachers need to become in-tune to their biases. However, data from this study does not suggest that an awareness to bias is enough to lead to changes in practice.

I certify that the Abstract is a correct representation of the content of this dissertation.

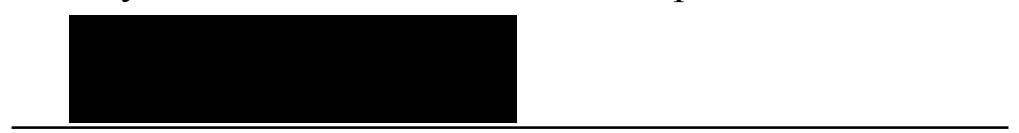

Chair, Thesis Committee

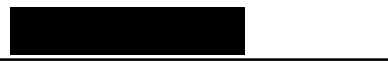

Date 


\section{PREFACE AND/OR ACKNOWLEDGEMENTS}

The work committed to this study, centered on teachers' implicit biases, was done with my bi-racial daughter, Natalia Marie Luczyk, and peers just like her, in mind. As she and others navigate a world that makes judgements about who or what they are capable of, based on non-academic factors, I want them to always be conscientious of this invisible thread - implicit bias - that can be made visible through their awareness and selfadvocacy. As I engaged in this work, as a single-mother, over a three year period, I thank and appreciate Natalia for being so willing to share my time, presence and emotions for a cause that is greater than the both of us. I would also like to thank my mother, Linda McRay, for instilling within me, at a young age, the importance of a solid education and for praying for and believing in me to accomplish this important task. Her unwavering faith in my ability to do exceedingly and abundantly more than I could have imagined is what kept me going throughout this tumultuous process. Her sacrifices for me as a child are what make me forever indebted to seeing her visions for and of me come to fruition and, for that, I am grateful.

I would also like to honor and acknowledge my dad, the late Sidney Smith, who unexpectedly passed away on March 23, 2020, about a month prior to my original dissertation defense date. He always had a dream and a vision of me becoming a Doctor and I know that my work in this field, and around this topic, will continue to make him proud. 


\section{TABLE OF CONTENTS}

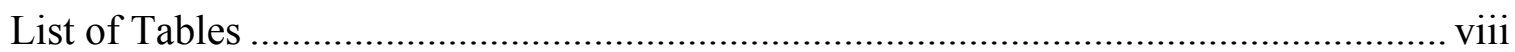

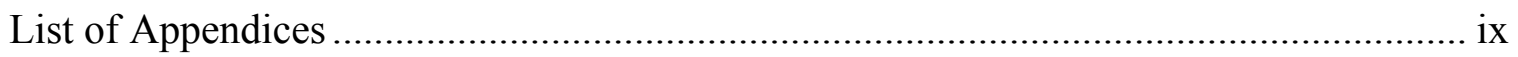

Chapter 1: Introduction and Problem Development ………...........................................

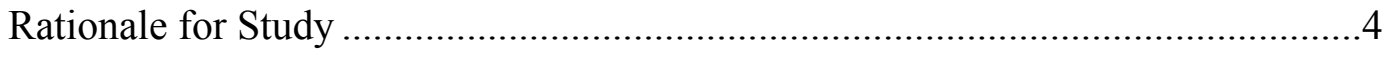

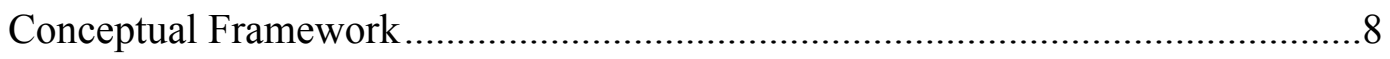

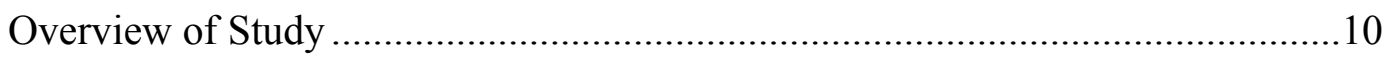

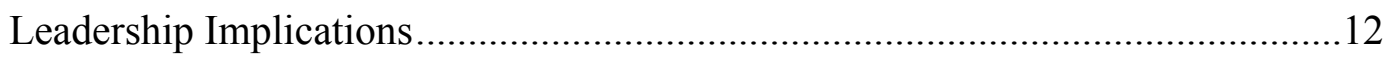

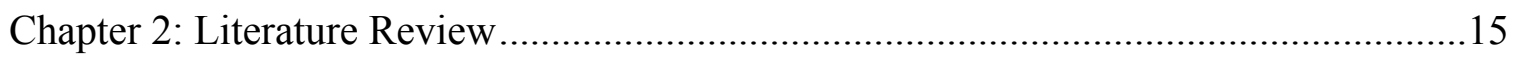

Impact of Implicit Bias on Learning Outcomes......................................................16

Implicit Bias and How it Shows Itself in Teaching ...........................................21

Tools for Measuring Implicit Bias...................................................................2

Teachers' Role in Addressing Implicit Bias in their Practice.................................28

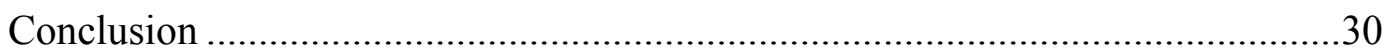

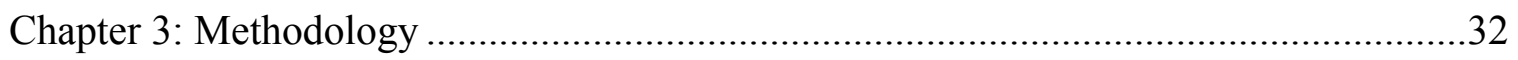

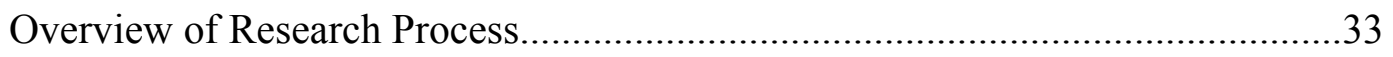

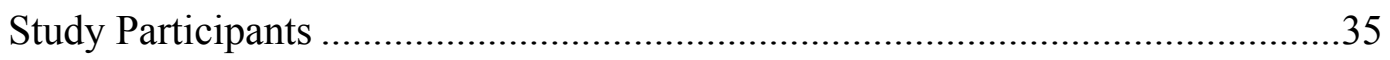

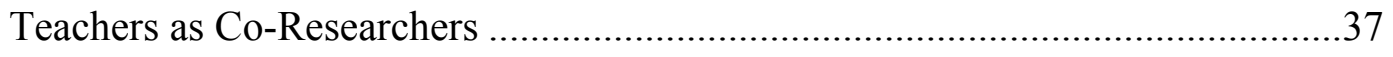

Ethics and Protection of Human Subjects.............................................................

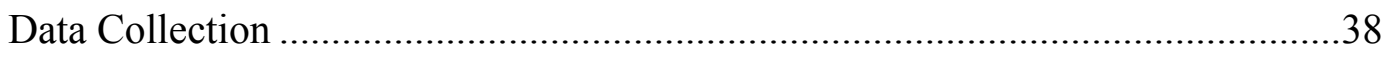

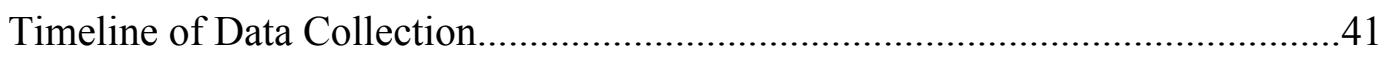

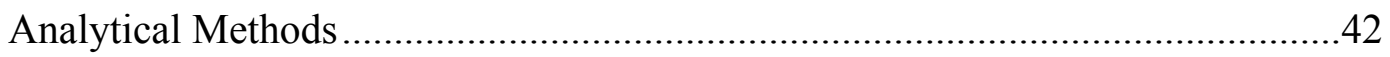

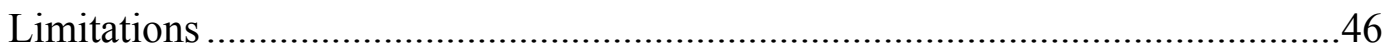




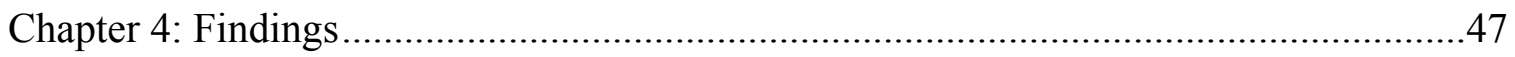

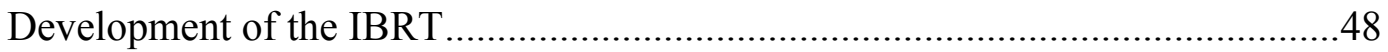

Case Study of Amber's Use of IBRT ……………...........................................52

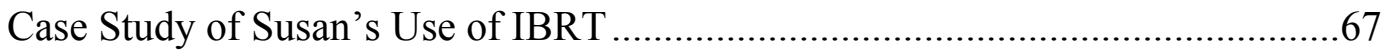

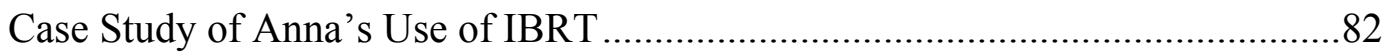

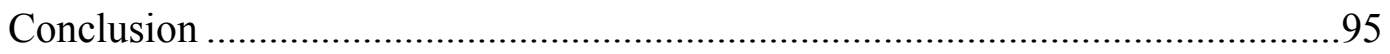

Chapter 5: Implications and Recommendations ……………......................................97

Interpretation and Synthesis of Findings ............................................................98

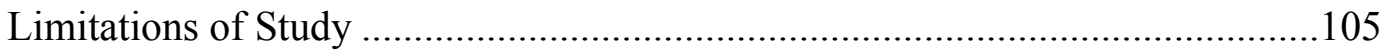

Recommendations for Action .......................................................................106

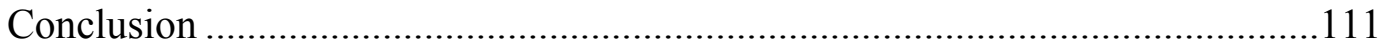

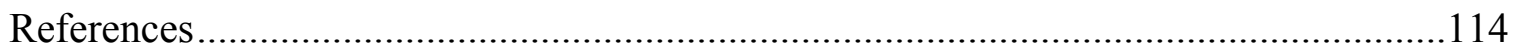

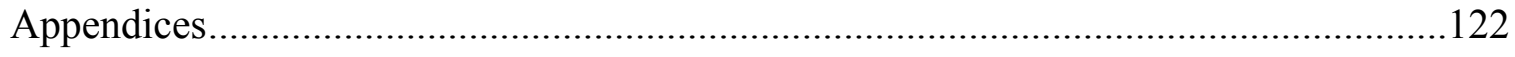




\section{LIST OF TABLES}

Table

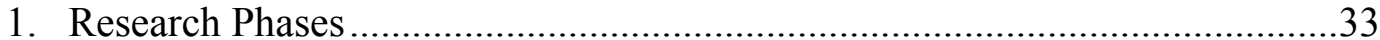

2. Phase 1 Outline for Participating Teachers ...................................................34

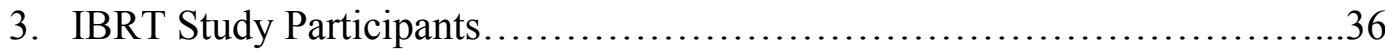

4. Initial Sample Coding Process ..............................................................43

5. Summary of Analysis by Phase ..................................................................45

6. Summary of Amber's Observations Using the IBRT ....................................55

7. Summary of Susan's Observations Using the IBRT ......................71

8. Summary of Anna's Observations Using the IBRT ......................... 85 


\section{LIST OF APPENDICES}

Appendix Page

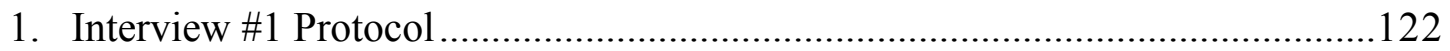

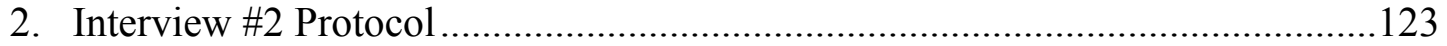

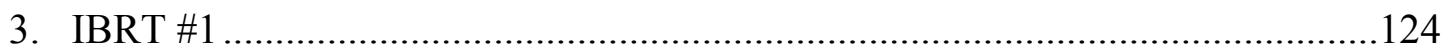

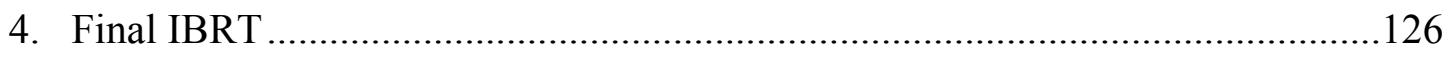

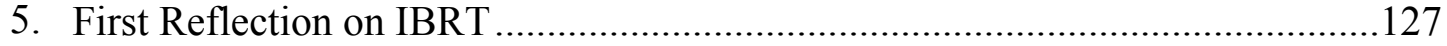

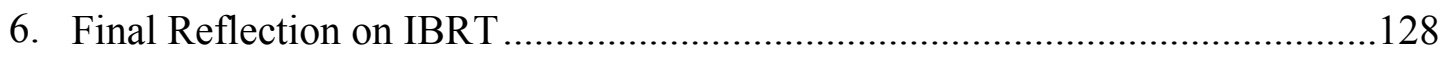




\section{Chapter One: Introduction and Problem Development}

From the time I was a child, growing up with a single mom, she made sure to instill in me the importance of a good education. Therefore, she made sacrifices that positioned me to be the best I could be. During my time as a child, I would always remember wondering why I couldn't attend public school with my neighborhood peers. Although my mother had nothing personal against public schools, she felt that private schooling would be the best fit for me. In her mind, she associated private schooling with better quality. She felt that there was a certain level of accountability that teachers held towards paying families. While my point is not to argue the validity of her thinking, I will argue that many of the teachers who were in the public schools were white and did not mirror a majority of the population in which they served - lower-class, black students. Therefore, the demographic mismatch created inequities that caused many black students to perform more poorly.

When times got hard, which they often did, my mom never failed to make sure that I was provided with the educational opportunities that I needed to flourish and be my best self. In fact, I vividly recall my mother selling my childhood home, just so that she could afford my private school tuition. This is just one example of the sacrifices that she made to ensure that I had a private-school education from preschool through twelfth grade.

One of the things that I came to realize as I grew older is that experience is the best teacher, and my mother worked to curate the experiences I was exposed to. 
Regardless of my mother's educational background, pursuits, etc., she had a vision of what a quality education should look like, and she used her knowledge and the resources she had to provide this for me. The reality, however, is that growing up in a middle-class household was an anomaly for my urban neighborhood and peers. In fact, many of my peers did not grow up with an abundance of resources and went to schools that mirrored that same reality. While the student body at the schools in my neighborhood was predominantly black and lower-class, a majority of the teachers that taught in the neighborhood were white and, like today, did not emulate the majority of the population that they taught and served. Growing up in the inner-city of Cleveland, Ohio was just that - inner-city living. These realities helped to shape my mother's perception of the type of education students received in my neighborhood - one that was just as grim as the city it served.

As an adult who now works in a field that employs a majority of white teachers, tasked to teach more minorities, I realize that what my mother was trying to shield me from was the implicit biases that many of the white teachers held towards the black students that they thought lived and breathed the same economic turmoil and deficits. These perceived deficits would go on to inform the way they thought black people could learn; what we were capable of understanding and, inevitably, influenced the way we were taught. While private schools did not employ any more blacks than the public schools, and biases didn't disappear, it seemed that parents' money validated their "voice". In turn, parents were more legitimized in their asks. 
I recall speaking to my neighborhood peers and asking what grades they received on their report cards, to which many of them would report failing marks. It would then prompt me to ask what it was they were learning, only to find out and realize that, although we were in the same grade, they were learning things that I learned grade-levels ago. As an adult, I now realize that many of them were receiving a watered-down curriculum, but with no correlation to higher grades. Experience and deductive reasoning tell me, in my mind, that the dominant workforce, which was white, minimized, devalued and lowered the expectations that they had for my black peers, which is why I want to understand the role implicit bias plays in minority students' academic achievement. How does stereotype threat infiltrate through the minds of black students and become evident in the work that they produce? What role does demographic mismatch play in determining black students' academic outcomes? Do teachers even believe that they carry implicit biases? If so, how do they define it in the first place? What does implicit bias look like in a classroom and what strategies work best at eradicating the byproducts of this mindset? Even with all of the sub-questions that I want answered, I have narrowed my focus to wanting to better understand:

- What are the impacts of a reflective tool intended to support teachers to notice and address implicit bias in their teaching practice?

The bottom line is that as we influence and cultivate a workforce of teachers, we need to ensure that we introduce them to the detrimental effects of implicit bias at the onset, so that they are more likely and prone to being conscientious of its negative impacts on 
black students. The foundational years for teachers provide an integral time for reflection and refinement - thus, what better time to bring these concerns to the forefront?

\section{Rationale for Study}

As early as the 1970 s, educational research began to look at the impact of teacher expectations on student outcomes (Rist, 2000). The most widely researched component for dissecting classroom-level bias is looking at teachers' expectations of students, based on the student's race/ethnicity and gender. In fact, Jacoby-Senghor (2016) conducted a study that shows that teachers' pro-White implicit bias scores predict the diminished test scores of black learners. Therefore, it is imperative that education researchers take a deeper look into how a student's race can and likely will influence their performance.

On a broader level, the data shows that we still need to address the inequalities that exist within our education system from a critical stance that identifies how bias impacts students' access to education. Although test scores are one way that some use to provide rationale for students' academic placements, with the mistaken assumption that tests are "neutral" regarding race, a student's race plays an unspoken role in decisions about placement and educational trajectory (Darling-Hammond, 2010). Students of color are over-represented in Special Education and under-represented in Gifted and Talented programs (Gullo, Capatosto \& Staats, 2019). Darling-Hammond (2010) notes that Latino students who scored above the $90^{\text {th }}$ percentile on standardized tests only have about a $50 \%$ chance of being placed in college preparatory classes, in comparison to near assured placements for their white counterparts. In fact, a study conducted by Robert Dreeben 
showed that students of color are more likely to receive lower quality of instruction, creating a racial gap in aggregate achievement by the end of the first grade (DarlingHammond, 2010).

Looking within the educational context of the institution that inspired this study, Oakland Unified School District (OUSD), their data illustrates the aforementioned academic performance narrative. OUSD is an urban district in California that serves approximately 36,000 students in 87 schools and employs a little over 2,000 teachers (Fast Facts, 2019). Within the student population, approximately $74 \%$ qualify for free or reduced lunch. The piece that corresponds with the literature, however, is the fact that almost half of the teachers in this urban District are white $-46 \%$; only $22 \%$ are black and $15 \%$ are Latino - and over $66 \%$ of its students identify as black or latino (Fast Facts, 2019; Teacher Data Snapshot, 2019).

If the District's 2017-2018 demographic makeup is similar to 2019-2020, then the academic performance of our minority students within OUSD mirrors national data. When looking at the 2017-2018 Scholastic Reading Inventory (SRI) results, it shows that only $10 \%$ of Latino students were reading at grade-level, with similar results, approximately 10\%, for African American students. Additionally, nearly half of both populations performed multiple years below grade-level (Reading Inventory Student Performance, 2018). The District's math scores for African American and Latino students paint a similar narrative. Looking at the 2018-2019 math Interim Assessment Block (IAB) scores, almost half of the population are below grade-level standards, while almost 
half of their white counterparts are above grade-level standards (Interim Assessment Block Results, 2019).

Therefore, when looking at the implications that a student's race has on their academic performance, researchers must uncover the rationale for why white students are able to academically outperform their minority peers. Taking a closer look at the effect a teacher's demographic mismatch has on minority student performance is one way to begin to understand the disparate outcomes. Additionally, taking a closer look at how implicit bias leads to stereotype threat with minority students is crucial as well.

Further, there are also other factors that influence the academic experiences of minority students. While the curriculum itself is one form of bias, individual instructors play a significant role in how the curriculum is enacted in the classroom and experienced by different learners. Davis, Mirick and McQueen (2015) explore the implications of their white privilege on their positionality in the classroom. They explain that as three, white female instructors, they must become and remain aware of the power differential that they often hold in classroom spaces and attuned to the multiple identities of their students and themselves. Without an instructor's understanding of their positionality, students are more susceptible to seeing less of themselves reflected in the classroom space. For example, Davis, Mirick and McQueen (2015) note that their positionality, as white educators, influence what they teach and how they teach it. The structures of oppression are often invisible; therefore, in order for students to challenge injustices, they must be taught to advocate for themselves in a way that helps them to combat dominant 
structures. In order to combat the oppression, however, the instructors must understand their positionality and engage diversity and differences in practice (Davis, Mirick and McQueen, 2015).

Students' experiences in school are based not just on the formal curriculum but also on the experiences they have based on nonacademic factors, such as how race, SES, and other demographics impact their identity, positionality, and access in classroom spaces. Stevens, Liu and Chen (2018) explain how discrimination toward racial and ethnic minorities serve as a key stressor in their academic outcomes. Microaggressions from peers and faculty, poor school climate and socially isolating environments all contribute to the diminished academic outcomes of minority students (Stevens, Liu and Chen, 2018). Therefore, it is critical to understand and address the stressors that may have a particularly profound effect on academic outcomes for students from different racial/ethnic minority backgrounds. Blad (2018) reports that if students do not feel like they belong, then they are at risk of succumbing to Impostor's Syndrome and believe that they are not capable of success. Therefore, like Stevens, Liu and Chen (2018), Blad (2018) argues that teachers must reflect on their positionality so that they don't inadvertently abuse their power.

As such, children who experience bias in school are likely to underperform, and, over time, this is a key factor in their persistence in school and often leads to inequitable outcomes for students of different races, even when they appear to have experienced the same schooling. Weissglass (2001) contends that many of the assumptions, values and 
practices of institutions hinder the learning of students of color and students from low socioeconomic backgrounds. In fact, race and class biases are the major causes of differential success. In fact, a report released from Georgetown University's Center on Education and Workforce (2019) notes that it is critical to understand the minority students do not lack the innate ability to succeed. The report contends that equally talented children from low-income backgrounds are often held back by material disadvantages, which are compounded by racial and ethnic inequities (2019).

\section{Conceptual Framework}

The adapted conceptual framework underlying this study builds upon W.E.B. DuBois' theory of Double Consciousness (DuBois, 1903). DuBois' idea of Double Consciousness argues that as African Americans, we are forced to look at ourselves through the eyes of the dominant oppression of Whiteness. He describes the inner turmoil that African Americans must endure as we attempt to hold on to our blackness and the rights that we must be seen as American, too. Furthermore, Du Bois attempts to explain the inner struggle felt by African Americans attempting to fit into a culture of Whiteness. Therefore, it was his hope that the African American race could be viewed as a legitimized duality, rather than from a lens of "Otherness" that causes us to be viewed as under the lines of humanity.

Although the results of this study show that students' race was rarely mentioned as a factor from which the participants' biases stem, students were still viewed in relation to the expectations/lens that these participants set for them. For example, the deficit 
associations that often paralleled the description of these students' behaviors were from the thoughts, opinions and views of the teachers who taught them. So, the mirror in which the students were viewed was merely from a lens of domination, or power that trumps the experience of the students.

In order to consider how teachers might better understand and mitigate the challenge faced by children encountering schooling through the experience of Double Consciousness, it is necessary to understand how educators come to change their practice. The theoretical cornerstone of this study relies on the theoretical underpinnings of the Transformative Learning Theory. Developed by Mezirow in the late 1970s, the Transformative Learning Theory is rooted in the idea of changing meaning to generate change (Biasin, 2018). In other words, the Transformative Learning Theory is a critical theory that describes adult learning and explains how self-knowledge and self-reflection are essential to emancipatory action and perspective transformation (Biasin, 2018). In fact, Mezirow posits that critical analysis is required to demystify implicit ideologies (Biasin, 2018). The premise of this current study centers on the need for teachers to become aware of the reification of hidden mechanisms of domination that suppress student outcomes. Therefore, such analysis must include a critical appraisal and reflection on the conscious and unconscious factors that affect their interactions. As such, the Transformative Learning Theory clarifies how the teachers in this study might work to appraise and disrupt their emerging understandings of implicit biases. The Implicit Bias 
Reflection Tool (IBRT) developed and tested in this study sought to engage participants in this process of critical reflection and change.

The research in this study builds upon Transformative Learning Theory, contending that if teachers are rooted in a culture of support that promotes self-reflection into their own practice, they will become more aware of the biases in their practice and this conscientiousness will lead to better connections with students. These enhanced connections mean that minority students are less subject to stereotype threat, teachers less likely to water down curriculum or expect less from students, students feel more welcome and are more present in this space. So, changing the "lens" through which students are viewed, while also holding up a mirror of introspection, I assume that we begin to ameliorate the disparate outcomes that many students face as a result of a lack thereof.

\section{Overview of Study}

Developing teachers' competence in a way that allows them to be deemed an effective educator is no easy feat. Developing their practice, coupled with having the best interest of students at heart means supporting those who are in constant contact with them (Durksen, Klassen, \& Daniels, 2017). Therefore, one of the most fundamental ways of supporting teachers' growth and development is by building an asset-focused system that empowers teachers, in and out of the classroom, to provide and receive regular, consistent, evidence-based feedback that improves their practice for students. An inability to effectively staff classrooms with teachers who have consistently engaged in reflective, anti-bias based strategies, creates a critical issue of equity. The disproportionately 
affected students are usually black and brown pupils who need reflective teachers the most but are often the ones going without.

Similarly, most teachers need a climate of support and resources to keep them willing and able to overcome the exceptional challenges of teaching. As a result of many teachers feeling unequipped to handle the challenges of teaching students, whose outcomes they feel disempowered to change, their biases may overshadow the power of cultivating an equity lens. Therefore, in my professional opinion, teachers who are in their primary years of teaching benefit most from the additional support that allows them to keep the self-reflection of their practice at the forefront. For example, Watkins (2010) asserts that without a strong learning community that supports new teachers, schools are at risk of higher turnover rates, inevitably contributing to a negative impact on student achievement. Furthermore, he notes that novice teachers can become disconnected from school goals when they are passive observers, siloed to their own classrooms.

Therefore, this study explored how and if a small group of volunteer teachers noticed and addressed implicit bias in their teaching practice, and what supports allowed them to do this more effectively. I will be using a qualitative, multi-phase approach to engage in co-research with this group of teachers. This research will help them to identify the biases in their practice and support them with addressing it.

As such, I conducted my research in three phases. Phase One, in Spring 2019, was a pilot phase with the goal of familiarizing participants with technologies and procedures to document their practice and to gather baseline data about the participating teachers. 
During the Summer of 2019, I developed the Implicit Bias Reflection tool, building on existing tools, research and data from phase one. In the third phase, fall 2019, I tested the newly developed tool with the same group of teachers as part of the self-studies they engaged in as the culminating experience in their MA program. These phases allowed me to engage in the participating teachers' practices and calibrate our findings, via reflective strategies, that later informed the creation of the IBRT.

\section{Leadership Implications}

Challenging inappropriate uses of power that often plague black and brown students who are under the tutelage of demographically mismatched teachers requires the lens of a transformative leader. At the heart of transformative leadership is the notion of liberation, empowerment and social justice (Shields, 2010). Thus, a transformative leader links education and educational leadership within a wider social context, by critiquing inequitable practices and working to create a socially just environment (Shields, 2010). Shields (2010) lists seven elements of transformative leadership, but for the purposes of this paper, I will mention two to expound upon.

One of the first elements of a transformative leader is one who attempts to effect deep and equitable change (Shields, 2010). Goldenberg (2014) says that because students of color are not typically members of the dominant culture, differences between students and the teacher can create environments where learning and teaching are difficult, resulting in subpar academic outcomes for minority students. Therefore, for there to be equitable changes in minority students' learning outcomes, the "process" 
of teaching and learning deserves greater attention, that a transformative leader must address (Goldenberg, 2014). For example, the effects that a teacher's implicit biases have on student achievement are often illustrated through the assigning of non-rigorous academic tasks. A transformative leader, however, holds the most promise in meeting the academic and social justice needs of a complex and diverse education system (Shields, 2010). In fact, a transformative leader would focus on disrupting and reshaping inappropriately ingrained knowledge and belief structures (Shields, 2010).

The other important element of transformative leadership, as defined by Shields (2010), is the deconstruction and reconstruction of frameworks that generate inequity. As previously mentioned, the higher a White teacher's anxiety when teaching black students, the lower their academic outcomes. Transformative leadership has the power to raise human consciousness in a way that builds meaning and addresses both implicit and explicit behavior that stems from dominant cultures and structures (Shields, 2010). When a transformative leader can create a space for advocacy in response to morally guiding principles, then that is when we can begin to see change.

Ingrained social beliefs often materialize as implicit bias, thus tainting pedagogical practices. The results of negative inferences that are made often disserve marginalized groups and fail to promote academic equality. Therefore, when students fail to meet certain standards, it validates racialized stereotypes and creates environments that could greatly benefit from transformative leadership. This study seeks to build and examine a tool to support educational leaders in taking up the issue of implicit bias in a 
way that grows and sustains effective practice among their teachers. While the study presented here is a small-scale pilot study to determine the effectiveness of a professional learning tool, the findings have the potential to inform leadership decisions regarding effective professional learning for teachers. This study also sets the stage for future research to examine the impact of anti-bias reflective practices at a school and systems level. This is one of my core goals as an educational leader, and thus, the findings in this study allow me to grow in effectiveness as I develop a research-based leadership agenda. 


\section{Chapter Two: Literature Review}

"[O]ur attitudes towards things like race or gender operate on two levels. First of all, we have our conscious attitudes. This is what we choose to believe. These are our stated values, which we use to direct our behavior deliberately ... But the IAT [Implicit Association Test] measures something else. It measures our second level of attitude, our racial attitude on an unconscious level - the immediate, automatic associations that tumble out before we've even had time to think. We don't deliberately choose our unconscious attitudes. And ... we may not even be aware of them. The giant computer that is our unconscious silently crunches all the data it can from the experiences we've had, the people we've met, the lessons we've learned, the books we've read, the movies we've seen, and so on, and it forms an opinion."

- (Gladwell, 2005)

The topic of implicit bias is an abstract concept. Because its remnants are byproducts of something that may not be "seen", research shows that this invisible construct has detrimental effects on the academic outcomes of minority students. As such, the conversation is more so about the lens through which our minority students are viewed and engaged. Therefore, by virtue of its invisibility, it is important to understand how it shows itself in teaching so that it can be identified and named. However, in conjunction with identifying implicit bias, one must also know how to measure something that is only indirectly visible. Given the nuances of this phenomenon, critical conversations around identifying, measuring and eradicating biased associations must be had. Therefore, this review of pertinent literature around implicit bias will help us to better name actions as implicitly biased and determine action steps towards creating a space of critical consciousness around its presence and quest towards amelioration. 
In order to develop a tool that assists teachers in both recognizing and addressing issues of implicit bias in their own practice, I draw upon several areas of current research. First, I explore what is known about the impact of implicit bias on learning outcomes, since the magnitude of the problem drives the overall purpose of this research study. Next, I examine how implicit bias shows itself in teaching. In order to adequately address the impacts of implicit bias, one must be able to identify its characteristics. Then, because implicit bias is not directly visible, it is important to be able to understand how to conclude the presence of bias in the first place. Finally, as practitioners and researchers focused on reducing bias, it is necessary to understand how teachers can work to minimize bias in their practice.

\section{Impact of Implicit Bias on Learning Outcomes}

Marginalized students of color face unique challenges as they navigate educational settings rife with teachers who act upon their implicit racial biases. The expectations that teachers hold for students, or the beliefs that they hold about their academic capabilities, often cause their implicit biases to lead to stereotype threat for students. Stereotype threat is when conditions make it more likely that a negative stereotype will be confirmed about one's group (Steele and Aronson, 1995). As such, it is no secret that over sixty years after the U.S. Supreme Court declared segregation in

public schools unconstitutional, widespread disparities persist between the educational outcomes of blacks and whites (Nord et al., 2011). In fact, according to Steele and 
Aronson (1995), whenever an African American performs an academic task, they are at risk of being judged by a societal stereotype that questions their intellectual ability.

One reason that learners are subject to stereotype threat in classrooms is that often, children of color are judged less capable than their peers. Research shows that a phenomenon called demographic mismatch, or racial mismatches between teachers and their students, can reduce the expectations that some teachers have for students of color (Gershenson, Holt, \& Papageorge, 2016). Educators' implicit biases, or subconscious stereotypes and prejudiced attitudes towards marginalized and/or minority populations, are often illustrated through diluted academic performance tasks that fail to increase students' depth of knowledge. According to Boser, Wilhelm, and Hanna (2014), teachers have significantly lower expectations for the academic achievement of minority students. Therefore, teachers who stigmatize certain students often modify how they teach and advise students, which can lead to poor educational outcomes and perpetuate gaps in educational attainment (Ferguson, 2003). As a result of these biases, many students of color fail to attain the same level of academic achievement as their majority, white counterparts.

Dee (2005) examines how systematic biases in teachers' expectations are related to the demographic match between the student and teacher. He found that when students are assigned to a demographically mismatched teacher, and one same-race or same-sex teacher, the demographically mismatched teacher is more likely to perceive the racially mismatched student to be disruptive, inattentive and less likely to not 
complete homework. Similarly, Ehrenberg, Goldhaber, and Brewer (1995) found that a teacher's race is likely to prompt stereotype threat or subjective evaluations of minority students. Gershenson, Holt, and Papageorge (2016) found that non-black teachers have lower expectations for black students than black teachers do. As a result of these and similar studies, I contend that demographic mismatch disproportionately affects the expectations white teachers have for minority and low-income students, creating adverse effects on their academic achievement. In fact, Jacoby-Senghor, Sinclair, and Shelton (2016) hypothesize that the higher a white teacher's implicit bias, the greater their anxiety when teaching black students, diminishing the quality of their instruction and, thus, student learning. They also note that the majority of minority students are taught by white teachers, creating a cumulative effect that significantly contributes to racial disparities in black and minority students' academic achievement. As such, the racial alignment of the teacher with the student is a large predictor of minority student outcomes.

Therefore, implicit bias should be examined through the lens of a students' race and the stereotype threats that they are likely to experience in classroom settings. With the legal end of segregation, I would have hoped that race would cease to have implications for students' learning experiences. Nevertheless, I argue that implicit racial bias alters the learning experience of minority students in a way that illuminates a dominant group's capital and social order. In Race Ethnicity and Education, Yosso (2005) points out that researchers, practitioners, and students are still trying to analyze 
the impact that race and racism have on US society. There is an underlying assumption that people of color lack the social and cultural capital to be successful in educational settings due to lacking knowledge, social skills, and capital. However, the objectification of black and brown students via academic and economic disempowerment perpetuates the cycle of subjugation. It is documented that experiences, histories, and resources revolved and continue to revolve around the European and Western hegemony (Quijano and Ennis, 2000). One of the many ways that minority students continue to be subjugated is through teachers who act on racial biases.

Implicit biases lead to academic disparities for students of color because students performing at lower levels than they are capable, due to stereotype threat, can reinforce the reduced expectations teachers hold for them. There is mounting evidence that proves that an educator's subconscious belief that one population is less likely to achieve than another can promote feelings of frustration and inadequacy, causing students to disidentify with educational environments, modify their expectations and behavior to conform to teachers' negative biases and lead teachers to modify how they teach, evaluate and advise students, leading to poor educational outcomes for the stigmatized student(s) (Steele, 1997; Ferguson, 2003). In an experiment done by Rosenthal and Jacobson (1968), false test data was distributed, and teachers attributed the "high achievers" to be among the better-resourced or wealthier students. The example is indicative of the expectation gap that stems from teachers' biases. On 
average, teachers have biased beliefs about student potential that stem from their demographics (Gershenson, Holt, \& Papageorge, 2016). Therefore, when students conform to low expectations, it perpetuates a cycle of underachievement or validates stereotype threat, which must be addressed.

Boser, Wilhelm, and Hanna (2014) also report that teachers have significantly lower expectations for the academic achievement of minority students. In fact, when students conform to negative characterizations it often compounds the biases. Steele and Aronson (1995) retort that repeated exposure to negative images of their ability breeds internalized inferiority complexes that negatively impact minority populations. As a result of these biases and exposure to teachers' negative images, many students of color fail to attain the same level of academic achievement as their majority counterparts.

The current system of official desegregation is built on a history of pushing out Black educators, which further exacerbates the problem of implicit bias toward children of color. The Brown v. Board ruling (1954) did end some of the overt racial discrimination in our country, but inevitably changed the racial makeup of the teaching workforce, creating environments rife with implicitly (and in some cases explicitly) biased teachers. Scialabba (2017) references Gladwell's Revisionist History podcast, Miss Buchanan's Period of Adjustment that highlights how there were unintended consequences of desegregation. He notes that as student populations changed, so did the teaching staff. When administrators went to staff newly integrated schools, white 
teachers were generally kept, while black teachers were let go (Scialabba, 2017). This led to black teachers being replaced by white, middle-class educators and black students who were disproportionately impacted by the racial mismatch. Therefore, that has led to perpetuation and even magnification of stereotype threat conditions, which has influenced some of the current racial bias trends that we see now, negatively impacting minority student achievement.

All in all, the effect that implicit bias continues to have on minority students leads to a justified need for an intervention. Demographically mismatched classrooms will continue to exist, therefore, there needs to be targeted teacher learning that directly addresses the remnants of this often-invisible phenomenon. Due to the inconspicuousness of implicit bias, we need to understand how to identify, measure and address its impact.

\section{Implicit Bias and How it Shows Itself in Teaching}

Research showing that implicit bias and stereotype threat are negatively impacting students lead to narrower questions of classroom practice: What does implicit bias look like in the classroom? How does one know if a teacher is acting upon their bias(es) in the classroom? Friedrich, Flunger, Nagengast, Jonkmann, \& Trautwein (2014) examine how teachers' expectations affect student academic progress. Like stereotype threat, they examined the Pygmalion effect, which is the effect that teachers' expectations have on students' future achievement. Brophy and Good (1970) described the cycle in which the Pygmalion effect evolves. One of the steps in the cycle says that 
teachers' beliefs about certain students begin to lead to preferential treatment, such as providing more attention and support to students, offering more challenging learning materials, interacting with the student longer, and being more responsive to the work of students for whom they hold high expectations. Since teachers are considered to be an important factor in the formation of a student's self-concept, this preferential treatment clearly impacts children's development as learners (Friedrich et. al, 2015). Good (1987) contends that teachers' expectations can be formed for an entire class, groups of students or specific individuals, although most empirical studies focus on the individual students or specific groups of students, like racial minorities or those from a lower-class background (Jussim et. al, 1996).

Because implicit associations are often held outside of conscious thought, even those with egalitarian beliefs can still act in a way that produces inequitable outcomes for different groups (Staats, 2016). There is evidence that shows that implicit biases are often activated by a person's race and/ or ethnicity and are held by everyone, regardless of their race or ethnicity (Staats, 2016). As such, Staats (2016) points out that there are several conditions where one might be more apt to act upon their unconscious bias: situations where there is ambiguous information given; when there are time constraints; and through fatigue or stress. Because many teachers encounter situations that mirror the circumstances, it is no wonder many students encounter the remnants of teachers' implicit biases. 
One way that implicit bias shows up in the classroom is through disparate discipline practices for students of color compared to their white peers. We subconsciously process a lot of information and beliefs about people that may be inaccurate and overgeneralized (Wright, 2016). For example, in a 2016 study conducted by the Yale Child Study, preschool teachers looked for problem behaviors in four children: a black boy and girl and a white boy and girl. Although none of them exhibited problem behaviors, the teachers spent a disproportionate amount of time searching for problem behaviors in black boys. Although they did not say that they believed the black boys were challenging, their actions were a reflection of their biases. The overgeneralization is common in education and tends to drive how majority populations interact with low income and minority students, leading to detrimental academic outcomes.

Infractions described as disruptive or disrespectful are ambiguous. Therefore, as previously noted, when something is subjective, it can lead to interpretations that are formed based on unconscious associations that are shaped by teachers' prior experiences (Staats, 2016). As a result, the discipline disparities that students often face are predicated on their race. Students of color are more likely to be sent to the office based on subjective evaluations of their behavior, while their white counterparts are often disciplined for more objective behaviors, like smoking or vandalism (Staats, 2016). In fact, black students are 2 to 4 times more likely to be referred to the office than white students and tend to receive more severe punishments than white students 
(Kaufman et al., 2010; Skiba, Michael, Nardo, \& Peterson, 2002). The time that teachers spend addressing subjective behaviors detracts from the instructional components of the class and disproportionately affects minority students.

Another way that implicit bias shows up in the classroom is through the discrepancy of academic performance between minority and majority students with similar academic profiles (Cate, Krolak-Schwerdt, \& Glock, 2015). McCombs and Gay (1998) contend that teacher judgments are affected by the race of the student. For example, tracking, or the determination of which educational pathway a student should take, is supposed to be determined by a student's performance or ability (Haller 1985; Oakes and Guiton 1995). However, research indicates that tracking decisions are generally made based on non-academic variables, such as students' race (DeMeis and Turner 1978; Harlen 2005; McCombs and Gay 1988; Parks and Kennedy 2007). As a result of subjective determinations, many minority students yield incorrect tracking decisions, which lead to lower tracks (Klapproth et al., 2012).

More specifically, a study was conducted in Germany where teachers' implicit attitudes were examined towards immigrant students with special education needs (Cate, Krolak-Schwerdt, Markova, \& Glock, 2016). They argued that inclusive education requires teachers to be prepared and willing to adopt and implement bestpractices based on the individualized needs of all students (Watkins, 2012). However, what they found was that classroom situations with students of immigrant backgrounds receive less-positive nonverbal feedback than students without immigrant backgrounds 
(Cate, Krolak-Schwerdt, Markova, \& Glock, 2016). In turn, it created environments where stereotype threat loomed among this population of students. Consistent with many other researchers, Tenenbaum \& Ruck's (2007) meta-analysis revealed that teachers used more affirming and neutral speech with European American students than with students having ethnic-minority backgrounds. As such, an effective implicit bias reflection tool would help teachers to reflect on: Who gets disciplined and how; Who gets acknowledged and how (i.e. who gets called on, type of question asked, response of teacher to student talk, etc.); How groupings are determined and how teacher characterizes performance and aptitude of individuals.

\section{Tools for Measuring Implicit Bias}

Directly measuring implicit bias is difficult to do in real-time classroom settings due to the very nature of implicit beliefs being only indirectly visible. In fact, the processes that lead to discourse around measuring bias often feels lofty and overcomplicated (Gullo, Capatosto \& Staats, 2019). Given these nuances, indirect ways to inform the discourse around implicit bias have been developed. The tool that continues to have the widest usage is the Implicit Association Test (IAT) (Gullo, Capatosto \& Staats, 2019). One factor that may lead to its wide usage could be the fact that it has free accessibility through Harvard's Project Implicit. Another key variable that likely leads to its wide usage is its reliability and validity data (Gullo, Capatosto \& Staats, 2019). However, one of the many reasons that I created a tool that can help teachers to notice and address implicit bias in their teaching practice is because, while 
the IAT helps its audience to gain a better understanding of how implicit bias is evident in specific interactions, its use does not directly connect awareness of implicit bias to practices such as those in classroom settings that could exacerbate or mitigate the impact of bias (Gullo, Capatosto \& Staats, 2019).

There are several researchers, however, who have successfully used the IAT to draw correlations between stimuli and prejudice, and these findings hint at how implicit bias and classroom actions are likely connected. A study by Arkes and Tetlock's (2004) confirms that implicit bias is, indeed, based on associations between race-related stimuli, and that outcomes generally favor white names and faces and associates African American names and faces with negative concepts. Similarly, in a nonempirical article, whose credibility might be limited, Bartlett (2017) found that 70 percent of people who take the race portion of the Implicit Association Test (IAT), said to measure one's implicit biases, prefer Eurocentric features to African American features. Despite the differences in peer review, or the lack of peer review, this common variable highlights the notion that a failure to acknowledge our prejudices can lead to discriminatory behavior. Arkes and Tetlock (2004) surmise that people who manifest high levels of bias on the IAT are guilty of harboring prejudice against African Americans. Additionally, Amodio's empirical study (2006) utilizes IAT as the tool of record to assess implicit stereotyping and racial bias. Amodio cites Greenwald, Nosek, and Banaji (2003) by saying that the IAT was chosen because it is known to be reliable and widely used in the implicit race bias literature. Although imperfect, and regardless 
of the tool's contention, the fact remains that we all carry biases that may or may not be acknowledged.

What the IAT does not do is provide insight into how the existence of bias translates into action or what teachers or others might do to reduce the impacts of implicit bias on their actions. The contention in Bartlett's research is whether or not one can conclude that a determination of bias on the IAT can measure who will discriminate against whom. According to Bartlett (2017), a measure of bias, via a tool such as the IAT, can, at best, determine how quickly someone is to correlate certain images to positivity or negativity; however, he asserts that tests like the IAT will not determine whether a person will act in a biased manner nor will the results be definitively consistent over time (Bartlett, 2017).

As such, it would be beneficial to have an "in-practice" tool that can help teachers to not only identify bias generally, but rather helps them identify potential bias in action, while also supporting a plan for change. In conjunction with the Transformative Learning Theory, which explains the learning process of constructing and appropriating new and revised interpretations of the way we experience the world, in order for transformation of thought to occur, there are a number of things that need to be present for a change in perspective to occur (Taylor, 2008). In order for a more fully developed perspective to take place, there needs to be a paradigmatic shift that allows one's thoughts be more inclusive, differentiated, permeable, critically reflective and integrative (Mezirow, 1996). Therefore, an in-practice tool would align with the tenets 
of the Transformative Learning Theory's approach because the tool would allow for teachers' critical reflection through the use of a type of reflective journaling, dialogue and critical questioning (Taylor, 2008). Challenging their thought processes and patterns through a real-time tool would promote a plan for real-time change.

\section{Teachers' Role in Addressing Implicit Bias in their Practice}

Any individual teacher action might be influenced by multiple factors, but taken as a whole, bias is impacting how teachers interact with and support/fail to support minority students. We know that bias is a significant contributor to inequitable outcomes, but we have limited knowledge of how to address this. Therefore, we need to re-wire the associations that we have formed that lead to inequitable implications on minority student achievement. As such, I contend that there are at least three things that teachers can do to begin to ameliorate the biases in their practice:

- Use critical self-reflection as a tool for teacher growth (Cimer, Cimer \& Vekli, 2013)

- Have access to conditions/ structures that support their self-improvement (i.e. intergroup contact - Gullo, Capatosto \& Staats, 2019)

- Be open to accessing counter-stereotypical exemplars (Gullo, Capatosto \& Staats, 2019)

Decision-making supports simply offer a buffer that can positively influence the detrimental effects of a teacher's higher, cognitive load. 
Using critical reflection as a tool for teacher growth allows teachers to pay attention on purpose. Authors Cimer, Cimer \& Vekli (2013) found that reflection increases greater self-awareness and can lead to change in practice. Day (2001) also argues that teacher reflection is necessary for the improvement of practice. Reflection compels teachers to critically appraise themselves, their beliefs and attitudes and their relationship between themselves and their students (Boud, Keogh and Walker, 1985; Lange, 1990). To extend the argument, critical self-reflection is questioning the broader structures of society - an ability to stand outside of their practice and see what they do from a wider perspective. It also allows them to see how the dynamics of power are at play in their practice (Nicholas, Tippins, and Wiesemen, 1997).

Further, having a communal learning structure would aim to eradicate the siloes teachers often work within (Byrk, 2016). Implementing intentional structures that allows teachers to use each other as sources of support, share best practices and norms around students' goals, expectations, curriculum and data, may enrich their praxis and, ultimately, improve student achievement. Gullo, Capatosto \& Staats’ study (2019) promotes the idea of intergroup contact, an idea that emerged through the work of Gordon Allport (2019). Allport's work revealed that interacting with a diverse group of people is one of the best ways to combat prejudice and stereotyping. As such, developing meaningful relationships, through intergroup contact, helps us to see people as individuals rather than a representation of a larger group or identity (Gullo et al. 2019). 
Allport points out that as long as the intergroup contact exists under low-anxiety conditions, where empathy is present, this strategy can be effective (Gullo et al.2019).

Lastly, many of the stereotypes that are formed stem from unconsciously internalized stereotypes that exist in our society. Countering the ideas that have been formed about a group or groups of people can potentially be replaced by positive images of a particular group or groups of people. Gullo et al. (2019) define counter-stereotypical exemplars as information, images and/or narratives that defy stereotypes and expectations. As such, reflecting on counter-stereotypic exemplars can reduce implicit bias (Blair \& Banaji, 1996; Columb and Plant, 2011). Being exposed to new narratives can help one to unlearn our biases.

\section{Conclusion}

All in all, my study built upon on the strategies identified through prior research into both implicit bias and reflective practice to help novice teachers to notice and address issues of implicit bias in their teaching practice. Implicit racial bias and stereotype threat alters the learning experience of students in a way that illuminates a dominant group's capital and social order. As a result, academic disparities are highlighted when pedagogical effectiveness favors one race over the other. An educator's subconscious belief that one population is less likely to achieve than another, can promote feelings of frustration and inadequacy, thus leading to the sub-par academic achievement of a lot of minority students. 
This review of literature demonstrated that there is a critical role that teachers must take in addressing issues of implicit bias in their practice. In order to notice and address implicit bias in their work, they needed to engage in critical self-reflection as supported through the creation of my Implicit Bias Reflection Tool (IBRT); they needed access to supportive structures that support their self-improvement, as supported by my co-observation and dual reflections; and, they needed to be open to accessing counter-stereotypical exemplars as evidenced through the analysis of in-classroom counter-narratives.

Therefore, my Implicit Bias Reflection Tool (IBRT) was a means for data collection and reflection. The goal was to see if/how their reflections led them to respond to the overarching questions of: Do teachers believe that they carry implicit biases? If so, how do they define it in the first place? What does implicit bias look like in a classroom and what strategies work best at eradicating the byproducts of this mindset? Even with all of the sub-questions that I wanted to answer, my primary focus was to better understand: What are the impacts of a reflective tool intended to support teachers to notice and address implicit bias in their teaching practice? The teachers' use of the IBRT and their answers to the prompts helped me, as the researcher, to better understand what changes, if any, needed to be made to support teachers in being aware of their biases and the next steps that might need to be taken. 


\section{Chapter 3: Methodology}

This in-depth study involved co-research with three teachers who were exploring the role of implicit bias in their own teaching practice. I engaged these teachers in the critical self-reflection of their teaching practice, by engaging in a process of reflecting on their practice through the lens of identifying potential bias, using a pilot version of a tool developed for this purpose. Critical self-reflection is the way in which we challenge our assumptions, interpretations and beliefs through self-reflection (Mezirow, 1997).

Through this method, teachers were led through a series of discussions and prompts that helped them to look introspectively into how their teaching might influence student outcomes. The subjective reframing that they went through was aligned to the tenets of critical self-reflection (Mezirow, 1997).

The Implicit Bias Reflection Tool (IBRT) was developed based on analysis of initial data from interviews with teachers using an existing video observational tool, the Equip Rubrics. The IBRT was designed to lead the participants through critical selfreflection via a series of prompts that helped them to name and challenge their assumptions by self-assessing their beliefs. Based on the outcomes of their initial selfreflection, and with the use of literature around this topic, I created the IBRT, aimed at helping them keep their biases at the forefront of instruction and student interactions, with the hope of helping them to become more conscientious of how these interactions can affect student outcomes. I then tested the tool that I developed, in hopes that their input would help me to refine and redefine what it means to be an effective teacher, 
conscious of their implicit biases. This research unfolded in three phases, as outlined in Table 1.

Table 1

Research Phases

\begin{tabular}{|l|l|}
\hline Phase I & $\begin{array}{l}\text { Co-observe teaching practice using Equip tool and } \\
\text { video recordings. Talk about observations, together, } \\
\text { to determine next steps. }\end{array}$ \\
\hline Phase II & $\begin{array}{l}\text { Develop a tool to support positive action to address } \\
\text { implicit bias, based on observations from Phase I and } \\
\text { literature }\end{array}$ \\
\hline Phase III & $\begin{array}{l}\text { Test the tool with subjects, in order to establish } \\
\text { validity and determine effectiveness }\end{array}$ \\
\hline
\end{tabular}

\section{Overview of Research Process}

The first phase of the study allowed me to have a better understanding of how each participant described and identified implicit bias as applied to their teaching practice, which gave me insight on the components a potential Implicit Bias Reflection Tool would need to contain. First, participating teachers familiarized themselves with Equip, an online observation tool used to track student participation, to build a more equitable classroom. At the same time, participating teachers recorded their lesson via a video recording device. Once the lesson was over, the participating teacher gave me access to the Equip classroom data and the recorded lesson. I and the teacher used the existing tool (Equip) to co-observe current teaching practices in context and assess the 
teachers' awareness of implicit bias. Seeing their video allowed me to analyze what I saw versus what the teacher saw, to gather a list of needs that my tool addressed.

In the second phase, I used the data from the pilot observations, coupled with existing research literature, to develop a specialized Implicit Bias Reflection Tool to support teachers in examining and addressing bias in their teaching. During this phase, I revised the tool, based on feedback from the willing participants. The third phase of the study involved testing the IBRT with the three study participants over an eight-week period in conjunction with the fall semester of their teaching year. The participants engaged in use of the IBRT as part of their completion of teacher research for their master's degree culminating projects. The whole premise of these three phases was to better understand: What are the impacts of a reflective tool intended to support teachers to notice and address implicit bias in their teaching practice?

Table 2 chronicles the process of collecting and analyzing data for Phase I, as shared with the participating teachers. The process of co-observation was completed once, as it was just a primer for the creation of the IBRT.

Table 2

Phase 1 Outline for Participating Teachers

\begin{tabular}{|l|l|l|}
\hline $\begin{array}{l}\text { Step 1: Record (on your phone or } \\
\text { device) one 30-45 minute lesson } \\
\# 1 \text { relating to your emerging } \\
\text { study in } 769\end{array}$ & $\begin{array}{l}\text { When: Once } \\
\text { during the week of } \\
\text { April 15-19th }\end{array}$ & $\begin{array}{l}\text { What: Send video to Silindra } \\
\text { at Silindra@gmail.com }\end{array}$ \\
& & \\
\hline
\end{tabular}




\begin{tabular}{|l|l|l|}
$\begin{array}{l}\text { Step 2: Using the same lesson in } \\
\text { step one, set-up your Equip } \\
\text { classroom, using the app (must be } \\
\text { done before you record). As you } \\
\text { teach your lesson, use the markers } \\
\text { identified in app so that it } \\
\text { automatically collects your data } \\
\text { for you. }\end{array}$ & $\begin{array}{l}\text { When: On the } \\
\text { same day that you } \\
\text { record your lesson }\end{array}$ & $\begin{array}{l}\text { What: After lesson \#1 is } \\
\text { over, use app to generate } \\
\text { Equip analytics (i.e. results) }\end{array}$ \\
\hline $\begin{array}{l}\text { Step 3: Give Silindra access to } \\
\text { your Equip results so that she can } \\
\text { review. }\end{array}$ & $\begin{array}{l}\text { When: by April } \\
\text { 19th }\end{array}$ & $\begin{array}{l}\text { What: Look at Equip results } \\
\text { and reflect on the following } \\
\text { aspects of your results: } \\
\text { overall classroom-level } \\
\text { participation, individual } \\
\text { student-level participation } \\
\text { and demographic-level } \\
\text { participation }\end{array}$ \\
\hline $\begin{array}{l}\text { Step 4: Meet with Silindra to } \\
\text { reflect on outcomes }\end{array}$ & When: April 22nd & $\begin{array}{l}\text { What: Bring Silindra hard- } \\
\text { copy of your results and we } \\
\text { have a conversation about } \\
\text { what we saw }\end{array}$ \\
\hline
\end{tabular}

\section{Study Participants}

As a former Adjunct Professor in San Francisco State University's (SFSU)

Department of Elementary Education, I sought to do a self-study that would allow me to work with teachers who were currently in SFSU's Master's program, based on the phases described above. The participants are three teachers who were, at the time of the study, enrolled in their final semester of the SFSU MA in Elementary Education program and thus completing teacher research studies of their own practice as part of culminating experience requirements. All volunteered to participate in this study, first as [then] members of a class on teacher research for which I was the instructor (Phase 1) and then 
as part of their culminating field study experience (Phase 2). Each of these teachers were moving on to complete their Field Study course and wanted to look at how implicit bias might have been evident in their teaching practice. Therefore, they wanted to use the data from this study as a source of introspection into their practice as teachers. Below, is a table that gives specific information about each of the teachers:

Table 3

IBRT Study Participants

\begin{tabular}{|c|c|c|c|}
\hline & $\begin{array}{l}\text { Teacher (Anna) } \\
\text { Race: White }\end{array}$ & $\begin{array}{l}\text { Teacher (Susan) } \\
\text { Race: Asian }\end{array}$ & $\begin{array}{l}\text { Teacher } 3 \text { (AE) } \\
\text { Race: Filipino }\end{array}$ \\
\hline $\begin{array}{l}\text { Range of } \\
\text { Teaching } \\
\text { Experience }\end{array}$ & 7 years & 4 years & $\sim 2$ years \\
\hline $\begin{array}{l}\text { Grade-Level } \\
\text { Currently } \\
\text { Taught }\end{array}$ & $1^{\text {st }}$ & $6^{\text {th }}$ & Kindergarten \\
\hline $\begin{array}{l}\text { Teaching } \\
\text { Location }\end{array}$ & $\begin{array}{l}\text { Urban school in } \\
\text { the SF Bay } \\
\text { Area }\end{array}$ & $\begin{array}{l}\text { Urban school in } \\
\text { the SF Bay Area }\end{array}$ & $\begin{array}{l}\text { Urban school in the SF Bay } \\
\text { Area }\end{array}$ \\
\hline
\end{tabular}




\section{Teachers as Co-Researchers}

The teacher participants were not just "subjects" but were instead jointly engaged in meaning making around their own practice. They were collaborators in developing and testing a tool, the IBRT, that would be helpful rather than prescriptive. As such, the development of the IBRT was done with their needs in mind, as they all sought to explore the role that implicit bias played in their own teaching practice. The tool was co-created in that they provided input into how the tool worked and what needed to be improved, according to their needs and assessments.

During this study, the participants were also engaged in their own research.

Because this would be their first real research experience, an added goal in the completion of this study was to help them in completing their own research, which was all geared towards looking at how implicit bias might be evident in their teaching practice. For example, Amber wanted to better understand how her biases influenced her ability to be equitable in her interactions with students, particularly in math. She wanted to see whom she was calling on more; who she engaged more and how she determined groupings. Susan realized that her own, personal upbringing in school influenced her preconceptions about students' abilities. Therefore, she wanted to explore the role bias played in her interactions with students. Lastly, Anna wanted to see how her implicit biases influenced how she thought students did or did not connect to what she thought was culturally relevant, based on her determinations of a student's race. As such, the participants in this study were able to use the data that they submitted for this study in 
their own field study experiences. Their participation not only helped to inform their own research, but also framed the lens in which they took up bias in this study.

\section{Ethics and Protection of Human Subjects}

The Office of Research and Special Projects (ORSP) for San Francisco State University determined this to be "exempt" from regulatory oversight (See Appendix G). As such, the possibility of harm to participants was kept to a minimum. The participants were part of one of my classes at San Francisco State University, but volunteered to be in the study, based on their desire to look deeper into how implicit bias might be impacting their teaching practice. Participants were free to decline to contribute to this research or to withdraw from participation at any point without penalty.

Since participants were being asked to candidly share personal reflections about a topic that may be perceived as socially and politically charged, great care was exercised to maintain their protection and confidentiality. Therefore, safeguards were put in place to preserve the anonymity of participants' names, replacing them with pseudonyms. Secondly, the source audio, video, and electronic data files were and continue to be maintained in password- protected, encrypted files on a secured computer. No hard copies exist of any of the transcripts or source files.

\section{Data Collection}

I collected data in several ways. In Phase One, the use of 1:1 interviews; participants' reflective writing; and, co-observations of participant selected videos of practice, provided data on how participants defined and identified potential implicit bias 
in their teaching practice. These data sources allowed me to engage in dialogue with study participants around the following questions:

- What are some practices that you engage in to improve students' academic outcomes?

- How do you define implicit bias?

- What effects, if any, has bias played in your classroom?

- What are some ways that we can become conscious of our biases during the planning and execution of lessons?

Phase Three of the research process used data from participants' use of the IBRT itself, and this forms the primary data set for the study. Participants were asked to use the IBRT eight times over the course of the study, although actual participation varied from four to eight total uses. Data from the IBRT was supplemented by exit interviews in which I asked teachers to reflect upon how the IBRT had supported identification of implicit bias and how it might be improved to lead to positive changes in teaching practice. The data sources for Phases One and Three are described below.

\section{One-on-one Interviews}

At the beginning of Phase I and the end of Phase III, allowed me to better understand the teacher in a setting that was free from the judgment of other participants and without the influence of others' responses. The Phase One interviews took place twice, May 2019 and June/July 2019, and the Phase Three Exit Interviews took place in Spring of 2020. In the Phase One interviews, I sought to better understand who the 
participants were and how they viewed their biases, in conjunction with the Equip tool data, to better contextualize their understanding of what could be considered to be biased interactions. Their reflection, coupled with my understanding of bias through pertinent literature, helped me to synthesize and point out concrete actions that inequitably affected their students. Engaging with each teacher in a 1:1 format helped me to address whether or not they think they engaged in a biased action; what they described as a biased interaction/action; what the bias looked like in the classroom and how it affected their students.

\section{Reflective Writing}

Reflective Writing was supported through use of the IBRT in Phase Three. This format allowed for extended thinking time and for teachers to express thoughts that may not have been formulated and developed to be spoken verbally. Written reflection prompts on the IBRT were developed to allow for authentic responses that are not as prone to the intimidation that one on one interviews might bring. The IBRT prompts were developed to guide participants through a scaffolded process of considering what they chose to notice about students, how they responded to what they noticed, how bias might play a role in their observations and actions, and what next or alternate steps they might take. The initial IBRT protocol is included in Appendix C, and the revised version is included in Appendix D.

Participants were also asked to reflect directly on the IBRT (Appendix E), and this data was used to revise and improve the tool. In their writing, they addressed their 
thoughts around the usability of the IBRT: Who worked well? What was difficult? How could the tool be improved? Then, after their completion of the study, they were asked to reflect on several questions (Appendix F): In what ways did you find using the IBRT helpful? Do you feel it helped you notice implicit bias and make appropriate changes? What do you plan to do moving forward to continue to build awareness of bias and address the issues that arise?

\section{Timeline of Data Collection}

The timeline for data collection was as follows: April 2019 I created an interview protocol (Appendix A) that allowed me to get a better understanding of the teachers and who they were. I was able to gain contextual knowledge that helped me to better conceptualize them, as teachers. Then, later in April 2019, I created a process for the teachers to engage with the Equip Tool (Table 2), that included a timeline, in order to get participants acclimated to the study and primed for next steps. After teachers recorded their lessons, I began to meet with them to ask for their responses to the following questions (Appendix B): Who didn't do as you expected? Who struggled to stay on task? How were groupings determined? How would you describe X's performance? Who would your focal students be and why? Is there anything else that stood out? What I was looking for was whether or not they tended to focus on the visible/physical indicators of being off-task; What they chose to pay attention to; What did they not yet pay attention to; Whether or not the teachers considered going deeper into their understanding of who they "attended to" and why; How I could support them in investigating their biases for 
themselves; Whether or not they realized which students they didn't notice enough; How they described students who were, in their estimation, "off-task"; In what ways they were open to critical self-reflection.

Based on their responses to those questions, I used them to inform how I went about creating the first draft of the IBRT (Appendix C), which was in August 2019. Later in August 2019 and into September 2019, I revised the IBRT and developed what became the final IBRT (Appendix D). The IBRT was sent to the three participants in September 2019. In order to see if there were any immediate changes that needed to be made to the IBRT, I asked the participants to complete a reflection on how the process was for them they completed this in September 2019. They then recorded their data from September 2019 through November 2019. Data analysis took place from December 2019 through February 2020.

\section{Analytical Methods}

A consistent process for analyzing data was used across the scope of this research project. For all phases of the project, a Grounded Theory approach to analyzing data was employed. More specifically, I utilized the tenets of Charmaz' (2014) coding approach to go through each phase of analysis. Phase I of this study utilized an initial coding approach, which Charmaz (2014) describes as the study of fragments of data that are used for analytic import. For example, when I began to code the Equip interviews, it was a starting point for gaining more context into each teachers' philosophy and narrative. Then, the codes that were generated for each of the teachers' interviews were compared 
with the codes generated from my perspective of their video lesson. Because $2 / 3$ of the codes developed from the initial video was centered on teachers' perceptions of students' behavioral complexities, my goal was to create a tool that attempted to elicit a more wellrounded reflection that did not prompt for any one type of categorical response.

In Phase III of the study, I met with a colleague/mentor and both of us looked at the data separately, in order to compare what themes came up for us and, then, their subsequent categories. Although she developed her coding strategies using Nvivo, I, too, started with Nvivo, but chose to independently develop themes and categories through my use of pen to paper process-coding. One of the themes that arose from this process is summarized in Table 4.

Table 4

Initial Sample Coding Process

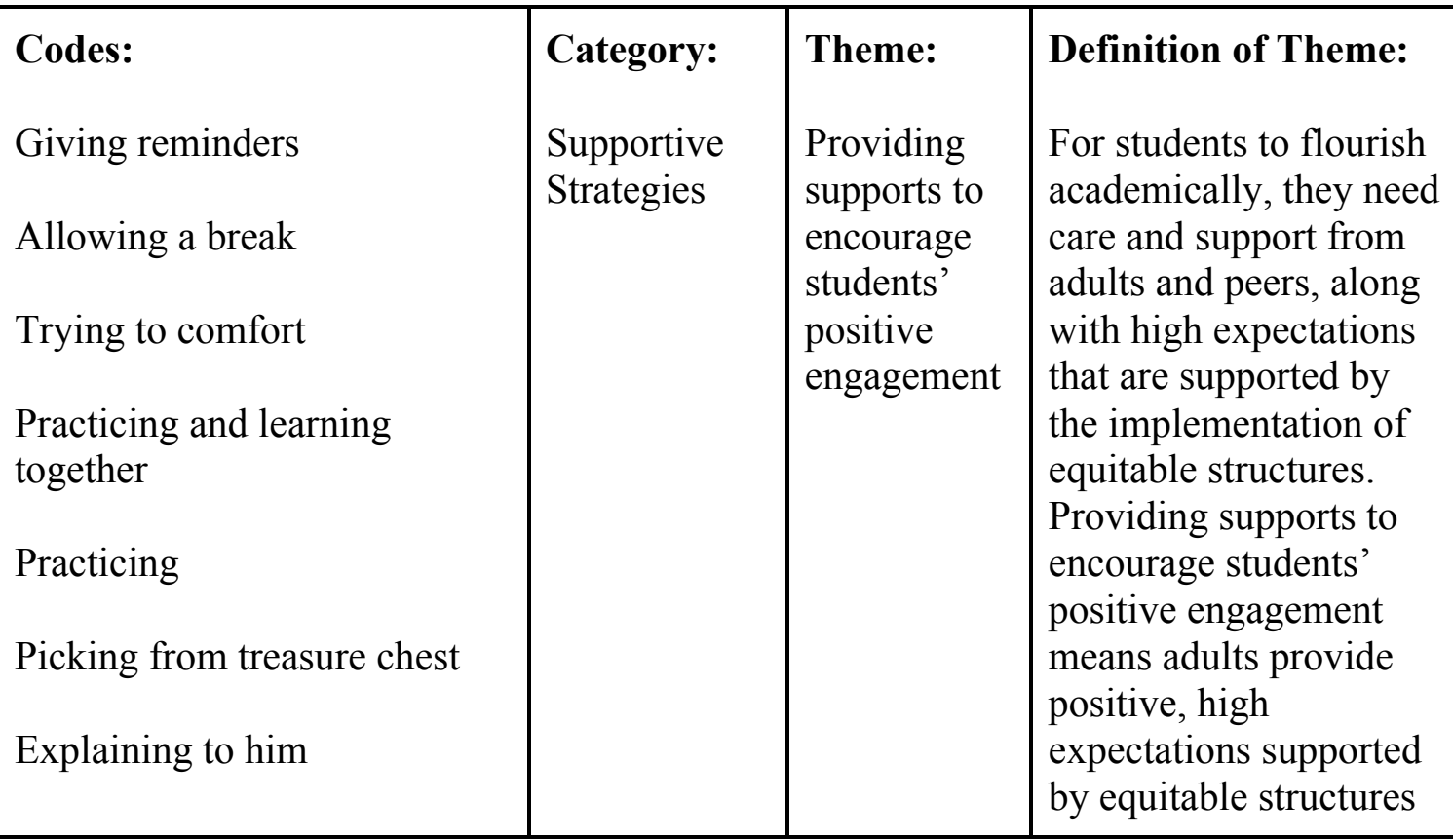




\begin{tabular}{|c|c|}
\hline $\begin{array}{l}\text { Asking him to cheer on } \\
\text { friends } \\
\text { Explaining to class } \\
\text { Asking them to cheer on } \\
\text { friends } \\
\text { Encouraging with rewards } \\
\text { Explaining fun in coloring } \\
\text { Trying to sit one-on-one } \\
\text { Doing work together } \\
\text { Asking if he was ok } \\
\text { Encouraging him to join } \\
\text { Moving to yellow on behavior } \\
\text { together } \\
\text { group } \\
\text { Encouraging to do some of } \\
\text { the work } \\
\text { Moving to orange on behavior } \\
\text { chart }\end{array}$ & $\begin{array}{l}\text { for achieving those } \\
\text { expectations for the } \\
\text { development of student } \\
\text { success and resiliency. }\end{array}$ \\
\hline
\end{tabular}




\begin{tabular}{|l|l|l|l|}
\hline Asking about work & & & \\
Asking him to write & & & \\
Giving a few reminders & & & \\
Asking student to explain & & & \\
Making effort to ease mind & & & \\
Explaining & & & \\
\hline
\end{tabular}

After I completed the code $\rightarrow$ theme $\rightarrow$ category process, for each teachers' response to each of the IBRT seven questions that the tool contained, I used the thematic analysis to develop a case study for each of the teachers.

Table 5

Summary of Analysis by Phase

\begin{tabular}{|l|l|l|l|}
\hline Phase & Procedures & Data Source & Analytical method \\
\hline 1 & $\begin{array}{l}\text { Meet with teachers twice, } \\
\text { May and June/July, to } \\
\text { gain contextual } \\
\text { knowledge of who they } \\
\text { are and analyze their } \\
\text { lesson via their Equip } \\
\text { data }\end{array}$ & $\begin{array}{l}\text { Record of co- } \\
\text { observation } \\
\text { (Silindra's detailed } \\
\text { notes) }\end{array}$ & $\begin{array}{l}\text { Code for match and } \\
\text { mismatch between } \\
\text { researcher and teacher } \\
\text { reflections }\end{array}$ \\
& $1: 1$ Interviews & $\begin{array}{l}\text { Identify key areas of } \\
\text { mismatch to develop more } \\
\text { supportive tool/ set of } \\
\text { practices }\end{array}$ \\
& Expert use of Equip \\
\cline { 3 - 3 } & $\begin{array}{l}\text { Teachers' use of } \\
\text { Equip }\end{array}$ & \\
\hline
\end{tabular}




\begin{tabular}{|l|l|l|l|}
\hline 2 & $\begin{array}{l}\text { Silindra's Implicit Bias } \\
\text { Reflection Tool } \\
\text { development based on } \\
\text { above + research } \\
\text { literature }\end{array}$ & N/A & N/A \\
\hline 3 & $\begin{array}{l}\text { Provide teachers with } \\
\text { Silindra's tool }\end{array}$ & $\begin{array}{l}\text { Written record of } \\
\text { teachers' use of } \\
\text { Implicit Bias } \\
\text { Reflection Tool }\end{array}$ & $\begin{array}{l}\text { Code for themes across } \\
\text { weeks } \\
\text { Identify key areas of } \\
\text { mismatch to refine } \\
\text { supportive tool/ set of } \\
\text { practices }\end{array}$ \\
\hline
\end{tabular}

\section{Limitations}

There were several limitations to this study. The first limitation is the size of the study. Although it would be difficult to generalize across a broad spectrum of teachers, students and educational settings, this study will provide detailed information on how individual teachers took up the ideas of implicit bias in their teaching practice. Having a subset of teachers examining this lens will lead to the development of a resource that will help others to do so as well. Additionally, the context of this study was limited to the demographics of teachers and students who only represent limited diversity compared to California schools. Lastly, this study measured the short-term effects of the Implicit Racial Bias Tool use with participants, which appeared to under-represent the potential long-term impact of implicit bias on students. 


\section{Chapter 4: Findings}

The following case studies examine the ways in which the three study participants took up the issue of implicit bias in their classroom teaching over a three-month period while using the Implicit Bias Reflection Tool (IBRT) as a means for data collection and reflection. The goal was to see how their reflections led them to respond to the overarching questions of: Do teachers believe that they carry implicit biases? If so, how do they define it in the first place? What does implicit bias look like in a classroom and what strategies work best at eradicating the byproducts of this mindset? Even with all the sub-questions that I wanted to answer, my primary focus was to better understand: What are the impacts of a reflective tool intended to support teachers to notice and address implicit bias in their teaching practice?

I first examine their education and teaching history, to compare the similarities and differences in each of the participants' backgrounds. A better understanding of their context and stories helps me, as the researcher, to assess the fluidity of the tool across different teaching backgrounds and trajectories. Additionally, a contextual understanding allows for certain inferences to be made about how their backgrounds might influence what they tend to notice and address.

It was interesting to see how each of the participants defined implicit bias initially, and how/if their definitions of the term changed as weeks progressed. As I previously stated, students' experiences in school are based not just on the formal curriculum but also on the experiences they have based on nonacademic factors, such as 
how race, SES, and other demographics impact their identity, positionality, and access in classroom spaces. Stevens, Liu and Chen (2018) explain how discrimination toward racial and ethnic minorities serve as a key stressor in their academic outcomes. As such, this tool looks at the impact reflection has on teachers' practice over an eight-week period in the hopes that helping teachers notice and reflect upon potential bias will ultimately improve the school experience for the children they teach.

\section{Development of the IBRT}

As previously mentioned, in Phase I of this study, I began to meet with the teachers to ask for their responses to the following questions (Appendix B): Who didn't do as you expected? Who struggled to stay on task? How were groupings determined? How would you describe X's performance? Who would your focal students be and why? Is there anything else that stood out? What I was looking for was whether or not they tended to focus on the visible/physical indicators of being off-task; What they chose to pay attention to; What did they not yet pay attention to; Whether or not the teachers considered going deeper into their understanding of who they "attended to" and why; How I could support them in investigating their biases for themselves; Whether or not they realized which students they didn't notice enough; How they described students who were, in their estimation, "off-task"; In what ways they were open to critical selfreflection. Based on their responses to the aforementioned questions, and what I gleaned from watching their recorded lessons, I began to develop the tool. 
The rationale behind the aforementioned questions posed is based on how I am defining implicit bias in this study. I defined implicit bias based on factors of the Pygmalion Effect; looking at potential disparate discipline practices and by highlighting discrepancies in the characterization and/or tracking of students' academic performance. Similar to stereotype threat, researchers examined the Pygmalion effect, which is the effect that teachers' expectations have on students' future achievement. Brophy and Good (1970) described how teachers' beliefs about certain students begin to lead to preferential treatment such as providing more attention and support to students, offering more challenging learning materials, interacting with the student longer, and being more responsive to the work of students for whom they hold high expectations. I wanted to have prompts that provided their rationale for their expectations of students.

In my video observations, I would look for indications of disparate discipline. In a 2016 study conducted by the Yale Child Study, preschool teachers looked for problem behaviors in four children: a black boy and girl and a white boy and girl. Although none of them exhibited problem behaviors, the teachers spent a disproportionate amount of time searching for problem behaviors in black boys. What I noticed during the first round of observations, coded in Table 4, was that the teachers, as a whole, seemed to desire that students display more docile characteristics. They tended to notice what they called "distracting" behaviors, so I wanted to create a tool that did not prompt for any one type of behavior, rather see what the prompts led them to describe. 
Lastly, I wanted to understand how students' academic performance was characterized, how students were grouped and described. Often times there are discrepancies in the academic performance between minority and majority students with similar academic profiles (Cate, Krolak-Schwerdt, \& Glock, 2015). McCombs and Gay (1998) contend that teacher judgments are affected by the race of the student. For example, tracking, or the determination of which educational pathway a student should take, or how they are grouped, is supposed to be determined by a student's performance or ability (Haller 1985; Oakes and Guiton 1995). However, research indicates that tracking/grouping decisions are generally made based on non-academic variables, such as the students' race (DeMeis and Turner, et al. 2007).

As mentioned, in Phase I of data collection, the participants put a lot of emphasis on supporting students to meet their desired behaviors, so what they tended to notice and address was what they described as distracting behaviors. Therefore, that generated a lot of questions for me, as the researcher. In fact, the first iteration of the IBRT contained thirty questions. One goal was to scaffold a practice that busy classroom teachers could work into their practice; therefore, I was tasked with narrowing down to what I deemed to be the most essential elements. The final series of seven questions (Appendix D) was centered on better understanding what it was that teachers noticed, whether it was student learning and/or behavior. I wanted to leave that up to them. I asked them to focus on just one student whose behaviors/interactions made them particularly noticeable to 1) keep the process sustainable and to 2) see what made that student the one in which they were 
compelled to talk about. Giving concrete examples of the student's action(s), that made them noticeable, by providing 3-4 concrete examples, would lead to more objective rationale.

In section II or the IBRT, I wanted to know how the teacher's assumptions of the student aligned with or detracted from their expectations of them. What were their expectations in the first place? Why was the behavior problematic and what behavior was preferred? Again, in Phase I, there were a lot of expectations for students to display docile characteristics, so I wanted to see how their expectations had the potential to lead to disparate practices and who was on the receiving end of those disparate practices, if any.

Finally, all of these teachers knew that they were engaging in this study to become more aware of how their implicit biases impacted what it was they noticed and addressed. Therefore, that meant that all of these teachers were aware that they held implicit biases in the first place - an important realization to authentically engage in this work. As such, I wanted the teachers to reflect on and name the factors that might have been at play when forming their interpretation of a student. Although I asked them to consider how the student's race, class and/or gender might have influenced their responses, it did not seem to matter because these teachers rarely mentioned race as a factor in their bias. 


\section{Case Study of Amber's Use of IBRT}

\section{Educational and Teaching History}

Post high school, Amber decided to attend a community college, although she did not know, at that time, where she wanted her career to lead her. One of her teachers recommended that she tutor students, which she did, and it led her to pursue her bachelor's degree in Liberal Studies at San Francisco State University. From there, she went straight into a teacher credential program. Now, Amber is a Kindergarten teacher who has been in this position since January 2019. Her first role as a formal educator was as a substitute, which began at the beginning of the 2018-2019 school year.

While Amber was part of the teacher credentialing program, she took a course called Practitioner-Based Research in the Elementary Classroom. In the course, she was interested in exploring how differentiating mathematics can improve student engagement. She had issues with higher-leveled math students growing "bored" with the math lessons and misbehaving and distracting other students as a result. Therefore, she was interested in how ensuring and maintaining engagement throughout the entire lesson can affect and possibly improve student behavior. However, she knew that her bias could potentially play a role in how and what she defined as "misbehaving".

\section{Initial Ideas about Bias in Teaching}

During the initial interview with Amber, in the Spring prior to her use of the IBRT, she defined bias as, "[The thoughts] that we encounter or come across subconsciously - something that you can be mindful of or reflect on or change...but it's 
hard to know it in the moment". She was aware that her own personal feelings towards a student could potentially affect her interactions with them. In fact, she stated, "I think - I feel like I can be emotional, so it can be draining to continuously call on the same child over and over and that can affect my interactions with them and cause a "'bias buildup"". As a result, she knew that she wanted to be conscious of her biases during the planning and execution of her lessons. Therefore, she wanted to take part in this study, to examine the impacts of a reflective tool intended to support teachers to notice and address implicit bias in their teaching practice, in order to be more conscientious of her impact on student achievement.

When Amber, who identifies as Filipino American, first began to take on issues of implicit bias in her teaching practice, through reflections she made after using the Equip Platform, she made some interesting observations. Equip is a video observation platform whose intended purpose is to track patterns of student participation, in an effort to empower teachers to create a more equitable classroom. The purpose of having the participants to engage in the Equip program, initially, was to have a common platform to serve as a baseline of discovery and analysis to be incorporated as I developed the IBRT. While engaged with the Equip program, Amber noticed that reflecting on a student(s) who "stood out" to her, based on their learning/behavior, as well as focusing on why they stood out, was a beneficial practice for her. If teachers are rooted in a culture of support that promotes self-reflection into their own practice, they will become more aware of the 
biases in their practice and this conscientiousness will lead to better connections with students.

In her initial discovery, she noticed that there were a lot more off-task students than she thought there were, and that she tended to notice only a small sub-set of these students. There were focal students whose behavior she thought stood out the most, but looking back via the Equip platform, she noticed that there were others doing things off task, as well, but didn't receive the same focus or attention from her. In fact, she stated, “I'm surprised I didn't notice [them] during the lesson”. Initially, her focal students were 5-6 beyond-level and approaching level math students, who were all boys and of mixed race or Asian descent. She noticed that the students she called on the most were her focal students and that there were a lot of differences between the boys and girls, in terms of who she noticed and addressed. In conjunction with the literature from Chapter 2, one way that implicit bias shows up in the classroom is through disparate discipline practices for students of color compared to their white peers. We subconsciously process a lot of information and beliefs about people that may be inaccurate and overgeneralized (Wright, 2016). For example, in a 2016 study conducted by the Yale Child Study, preschool teachers looked for problem behaviors in four children: a black boy and girl and a white boy and girl. Although none of them exhibited problem behaviors, the teachers spent a disproportionate amount of time searching for problem behaviors in black boys. Although they did not say that they believed the black boys were challenging, their actions reflected their biases. With this as a baseline, I anticipated that Amber's use of the IBRT 
might allow her to explore/examine/reflect on her feelings of bias in more detail, particularly regarding how she interacted with students during math class and how bias in terms of gender and race might play a role.

\section{Amber's Analysis of Bias in Her Teaching Practice using IBRT}

One of the limitations of Amber's involvement in this study is that she only completed four weeks of reflections over an eight-week period, thus limiting indicators of growth or change over time. Nonetheless, several clear themes emerged from her four completed reflections that indicate ways in which she both took up and potentially downplayed bias in her teaching practice. The main themes that are evident from her participation are:

1. An over-inference of students' motivations

2. Providing supports to encourage students' positive engagement

3. Showing Care

Most of her themes tend to stem from a focus on student behaviors. Table 6, below, summarizes the things that Amber tended to talk about as it relates to what she noticed and addressed in the classroom:

Table 6

Summary of Amber's Observations Using the IBRT

\begin{tabular}{|l|l|l|}
\hline $\begin{array}{l}\text { Date/Observation } \\
\text { Number }\end{array}$ & $\begin{array}{l}\text { Summary what the student } \\
\text { said or did that was } \\
\text { noticed/addressed (IBRT } \\
\text { Question } \# 3 \text { ) }\end{array}$ & Emergent Theme \\
\hline $9 / 11 / 2019-\# 1$ & Amber chose to discuss the fact & 1. An over-inference \\
\hline
\end{tabular}




\begin{tabular}{|c|c|c|}
\hline & $\begin{array}{l}\text { that one of her students yells out } \\
\text { while she is talking. She also } \\
\text { mentions how the same student } \\
\text { grabs another student and } \\
\text { continues even after being told to } \\
\text { stop. A while later, the student } \\
\text { jumps on another student's back } \\
\text { and, then, falls and scrapes his } \\
\text { elbow, becoming upset. }\end{array}$ & $\begin{array}{l}\text { of students' } \\
\text { motivations } \\
\text { 2. Providing supports } \\
\text { to encourage } \\
\text { students' positive } \\
\text { engagement } \\
\text { 3. Showing Care }\end{array}$ \\
\hline 9/22/2019 - \#2 & $\begin{array}{l}\text { Amber discusses how her } \\
\text { student, Michael, becomes upset } \\
\text { when she moved him behind } \\
\text { another student in line, in an } \\
\text { effort to form a single-file line. } \\
\text { She gave him reminders that he } \\
\text { will get a chance to be in the } \\
\text { front of the line. } \\
\text { A bit later, during their math } \\
\text { block, Michael was feeling } \\
\text { frustrated and had a hard time } \\
\text { persevering, when tasked with } \\
\text { writing his numbers.He dropped } \\
\text { from his chair to his knees, } \\
\text { crying. } \\
\text { Later, she stated that the table } \\
\text { with the most points at the end of } \\
\text { the week gets to pick from our } \\
\text { treasure chest. Michael was not } \\
\text { sitting at the table that got to pick } \\
\text { from the treasure chest this } \\
\text { week. Again, he fell from his } \\
\text { seat down to his knees and began } \\
\text { to cry, saying that it's not fair, } \\
\text { although the rest of the class was } \\
\text { also upset. }\end{array}$ & $\begin{array}{l}\text { 4. An over-inference } \\
\text { of students' } \\
\text { motivations } \\
\text { 5. Providing supports } \\
\text { to encourage } \\
\text { students' positive } \\
\text { engagement }\end{array}$ \\
\hline 10/7/2019 - \#3 & Amber points out how Jack & 6. An over-inference \\
\hline
\end{tabular}




\begin{tabular}{|c|c|c|}
\hline & $\begin{array}{l}\text { outwardly stated that he didn't } \\
\text { want to do the work. He } \\
\text { constantly pushed the paper } \\
\text { away or put it on the floor under } \\
\text { is foot. She tried to encourage } \\
\text { him with rewards in order to } \\
\text { participate, but he simply stated } \\
\text { that he didn't like coloring. He } \\
\text { simply chose to lay on the floor } \\
\text { and not complete the work. } \\
\text { Later that day, they did a math } \\
\text { activity -- count teeth on a jack- } \\
\text { o-lantern, write the number, } \\
\text { color, cut and paste in order. } \\
\text { Again, Jack chose to lay on the } \\
\text { floor -- making groaning noises } \\
\text { like he was bored. She tried to } \\
\text { encourage him, but that did not } \\
\text { work, so she told him he would } \\
\text { move to "yellow (think about it)" } \\
\text { on their behavior chart--he didn't } \\
\text { mind and continued on. She then } \\
\text { said she would move him to } \\
\text { "orange (teachers choice)" and } \\
\text { encouraged him to look at his } \\
\text { peers and notice how much fun } \\
\text { they were having. After } 3 \\
\text { warnings, she took time away } \\
\text { from free choice time. He said," I } \\
\text { don't care -- I want to go to "red } \\
\text { (parent contact)." }\end{array}$ & $\begin{array}{l}\text { of students' } \\
\text { motivations }\end{array}$ \\
\hline 10/16/2019- \#4 & $\begin{array}{l}\text { There were two incidents with } \\
\text { Jayden--one that involved him } \\
\text { pushing another student, and } \\
\text { another where he pulled another } \\
\text { student's hair--unfortunately both } \\
\text { incidents ended in tears. } \\
\text { In both cases, Amber talked to } \\
\text { Jayden and the other student }\end{array}$ & $\begin{array}{l}\text { 7. An over-inference } \\
\text { of students' } \\
\text { motivations } \\
\text { 8. Providing supports } \\
\text { to encourage } \\
\text { students' positive } \\
\text { engagement } \\
\text { 9. Showing Care }\end{array}$ \\
\hline
\end{tabular}




\begin{tabular}{|l|l|l|}
\hline & $\begin{array}{l}\text { involved. When asking Jayden to } \\
\text { explain the situation, he couldn't } \\
\text { really tell her and seemed to shy } \\
\text { away. She also explained to him } \\
\text { that it is not safe when they don't } \\
\text { keep their hands to themselves, } \\
\text { and he and others can get hurt } \\
\text { when playing games that are too } \\
\text { rough. }\end{array}$ & \\
\hline
\end{tabular}

Overall Amber's reflections tended to focus on describing students who engaged in individual behaviors she deemed inappropriate, and the largest parts of her reflections described providing support to encourage her preferred behaviors. Inappropriate behaviors specifically named included: physical aggression, physical contact, calling out, making noises, retaliation, being emotional, being unmotivated, being easily triggered, non-participation, unresponsiveness, and disinterest. As stated in Chapter 2, infractions described as disruptive or disrespectful are ambiguous. Therefore, as previously noted, when something is subjective, it can lead to interpretations that are formed based on unconscious associations that are shaped by teachers' prior experiences (Staats, 2016).

\section{Theme 1: Over-inference of Students' Motivations}

In her four reflections using the IBRT, Amber made ten references to the motivation behind students' actions. For instance, when describing students she felt did not want to do work, or behaved in what she perceived as a distracting manor, she made statements such as the following, in which she infers the reasons underlying specific behaviors [text coded for inference of motivation in italics]: 
- "He continuously chose to not participate. He was unmotivated, uninterested, and unresponsive to behavior management"

- "I feel that maybe something at home might be causing his actions or other students may be an influence"

- 'I'm wondering if he is attention seeking--although we have shown him positive attention and he did not respond very well”. (Observation 1)

As such, it appears as though she characterized most student behaviors in terms of her own assessment of what motivated a given student's action or response. Her reflections do not explain her reasons for the inferences made, and in most cases offer a single interpretation of motivation. It is not possible to determine from the data the accuracy of the inferences. However, there is evidence that she bases next steps and responses to behavior on these assumed motivations. If teachers are rooted in a culture of support that promotes self-reflection into their own practice, they will become more aware of the biases in their practice and this conscientiousness will lead to better connections with students. These enhanced connections mean that minority students are less subject to stereotype threat, teachers less likely to water down curriculum or expect less from students, students feel more welcome and are more present in this space. So, changing the "lens" through which minority students are viewed, while also holding up a mirror of introspection, I infer that we begin to ameliorate the disparate outcomes that minority students face as a result of a lack thereof.

\section{Theme 2: Providing Supports to Encourage Students' Positive Engagement}


In Amber's reflection, she appeared to have remained conscientious of what might be needed to promote students' positive engagement and interaction. Although she made a lot of inferences about the motivations behind students' behaviors, and the majority of these were negative (e.g. assuming a child was "uninterested,") she did indicate working continuously to support the behaviors that she wanted children to exhibit, and most of these accounts referred to positive supports. 19 instances in her reflections were coded as providing positive supports to upholding her preferred behaviors. For example, she notes things such as:

- "I allowed him to take a break while he calmed down"

- "I tried to encourage him with rewards in order to participate..."

In coding her data, her preferred student behaviors were for them to: understand boundaries with other students/self-regulation, be patient, control emotions, keep hands to self, and emulate peers' positive behaviors. In fact, throughout the analysis of her data, she made approximately nineteen references to the supports that she provided that were aligned with promoting her preferred behaviors. She noted doing things such as:

providing breaks, providing praise for positive behavior, and encouraging students with rewards.

Throughout Amber's reflection in the study, it appears as though her encouragement of students' positive engagement was centered around her desired behaviors, which were consistently described as being non-distracting and safe. In incidents that were coded as showing evidence of providing positive supports, Amber 
appears more able to reflect on potential bias than in incidents coded as inferring motivation. For example, in week one she first describes the behavior she would like to see from one of her students:

...I would prefer Tacio understand his boundaries with other children-not being close up to their faces, not following them around the class when they are trying to move to a better spot for them to focus, not grabbing other students, etc.

She goes on to describe the positive supports she tried:

As the days go by, I am looking for behavioral interventions. Today, we started our class flip chart. I may decide if an individual behavior intervention will need to be put in place.

She seems aware that bias may play a role in how she responds to the student, even if she is not yet able to act in accordance with this realization. In the IBRT prompt that asked her to reflect on how bias may play a role in how she views this student, she considers how her prior knowledge of the student might cause bias. She says,

Before meeting Tacio, I knew that he had visited with a school psychologist during TK. This might be a factor, but I try to walk in everyday thinking, "Today, will be a great day for Tacio.

She sees that her preconceptions about the challenges this student has faced factors into her expectations of him. She does not yet connect this insight to future action, but the awareness may be a first step in this direction.

In week four her preferred behavior of students stems from her desire of them to be safe, and the supports she provides stem from this basic requirement for classroom functioning. In her reflection she explains: 
I don't feel it's safe when students are playing too rough at school and that's what I explain to Jayden. He's been hurt before by another student, but it was because they were playing a game that Jayden wanted to play. I would prefer that he practice safe touch or simply keeping his hands to himself so as to not touch others inappropriately.

Whether Amber's desire for “appropriate behavior” stemmed from her disapproval of distractions, or her quest to promote student safety, she notes a couple of places where she attempts to avert their disagreeable actions. She says,

I tried to turn Tacio's behavior around by "randomly" choosing him and a couple other students to come up one-by-one and cheer for them and encourage them that they could be a good friend. I also praised his positive behaviors (A LOT..because I looked for them!!!!!) At the end of the day, I told him that I was proud that he turned his behavior around and explained how happy it would make me if he showed that behavior all day tomorrow.

In another instance she says:

It is to my knowledge that he likes to work one-on-one with me, but I've explained that I'm not able to work one-on-one with him for every activity -- sometimes we'll work together to get him started, I'll encourage him to keep going and I'll check back, but when I come back he hasn't finished any work one his own.

Despite her attempts to promote what she would deem acceptable behavior, both examples required her to be intentionally in-tune with individual students' behaviors, which may or may not be sustainable in a classroom with large amounts of students. Therefore, the unsustainability can lead to biased outlooks of what it means to be a "compliant" student.

As such, some of her assumptions of the students' behaviors seem to stem from her biases around desirable classroom behaviors. When asked how bias might inform her 
interpretation of the student's behavior, she says, "His parents have shared with me that Jayden has a younger baby sister. I might be assuming that Jayden is experiencing some jealousy and is lashing out at other students. When confronted, Jayden either cannot explain his side. There was a time when I observed Jayden get really upset with another student and pull him backward by the hood of his sweater because he wasn't following the rules of the game--I interpreted this action as a form of control on Jayden's part". In all examples provided, however, her reflection appears to be a key driver of her awareness of her biases.

\section{Theme 3: Showing Care}

An enlightening part of Amber's analysis is that there were eight instances where she showed care for her students, despite some of the internal challenges she has with some of their decisions. For example, she notes things such as:

- “...This might be a factor, but I try to walk in everyday thinking, "Today, will be a great day for Tacio."

- "...I try to comfort students as much as possible"

- "I'll encourage him to keep going and I'll check back"

- “...I did end up reaching out to his parents due to the severity, asked followup questions to learn more information about what might be causing this"

In these instances, she is showing that she wants to exhibit caring toward students and perhaps to build connections with them. While the instances coded for showing care tend to be brief, they appear across all of her reflections. The fact that she reports both feeling 
and demonstrating care in the form of encouragement, comfort, and reaching out to better understand students shows promise as Amber works to better understand how personal and systemic bias might be impacting her interactions with students.

\section{Amber's Awareness of Bias in her Practice}

Again, using critical reflection as a tool for teacher growth allows teachers to pay attention on purpose. Authors Cimer, Cimer \& Vekli (2013) found that reflection increases greater self-awareness and can lead to change in practice. Day (2001) also argues that teacher reflection is necessary for the improvement of practice. Reflection compels teachers to critically appraise themselves, their beliefs and attitudes and their relationship between themselves and their students (Boud, Keogh and Walker, 1985; Lange, 1990). To extend the argument, critical self-reflection is questioning the broader structures of society - an ability to stand outside of their practice and see what they do from a wider perspective. It also allows them to see how the dynamics of power are at play in their practice (Nicholas, Tippins, and Wiesemen, 1997).

When Amber was asked to consider how bias might be informing her interpretation, she seemed to be aware that she might be harboring biased thoughts about her students and she mostly explains her biases as assumptions that she might have been making, based on her prior knowledge of the students. For example, she notes:

- "Before meeting Tacio, I knew that he had visited with a school psychologist during TK. This might be a factor, but I try to walk in everyday thinking, "Today, will be a great day for Tacio." 
- "While I believe I'm empathetic and I try to comfort students as much as possible, this is not the first time Michael has cried over something that seems small from an adult perspective. I might perceive him as a "cry baby" type of student and I don't feel surprised when he becomes upset when he doesn't necessarily get what he wants"

- "Since I know that Jack used to have naps in the middle of the day, I might be preemptively expecting his energy to decrease by noon. I may be expecting Jack to already be making the transition to being in kindergarten all day--not needing a nap--since we are already going into our 6th week of school"

- "His parents have shared with me that Jayden has a younger baby sister. I might be assuming that Jayden is experiencing some jealousy and is lashing out at other students. When confronted, Jayden either cannot explain his side. There was a time when I observed Jayden get really upset with another student and pull him backward by the hood of his sweater because he wasn't following the rules of the game--I interpreted this action as a form of control on Jayden's part"

I found it interesting to note that she names bias as preconceptions and assumptions that she made about students, without always having concrete evidence that what she assumed about them is what factored into their actions. For example, in Observation \#1, she names Tacio visiting a school psychologist in a prior year as the basis for the assumption that he had some challenges worthy enough of visiting a psychologist, that it must be the cause for his behavior in the current year. Conversely, although she appears to be aware that 
assumptions drive her outlook of students, she does not yet go as far as to mention how her views inform what she considers to be appropriate and inappropriate behavior. In the example with Michael, she said that she might view him as a crybaby instead of attempting to understand the root cause of his actions. In accordance with the literature above, that talks about "an ability to stand outside of their practice and see what they do from a wider perspective" - from Observation one to four, it seems that her perspective of bias might still be narrow.

\section{Amber's Reflection on use of IBRT}

Amber had some insightful reflections when asked about the IBRT's helpfulness in reflecting on her biases. When asked whether the IBRT was helpful, she responded by saying:

This tool was helpful for me in reflecting back on my day and understanding which students stood out for that particular day, as well as helped me understand who I was targeting my attention towards. It also directed me to rethink the ways in which I was giving students attention whether it be positive or negative.

The promise that her realization provides helps work towards combating the detrimental effects of the subconscious information and beliefs that we process about people that may be inaccurate and overgeneralized (Wright, 2016).

Therefore, I was curious to know whether she felt that the IBRT helped her notice implicit bias and make appropriate changes. To that she responded by saying:

I feel that it helped my notice implicit bias to an extent. It helped me understand the "standout" student that day and reflect on the ways they did stand out. It made me realize that there was a lot of attention being spent on behavior and I found myself writing about incidents that required some kind of consequence, as opposed to writing about students who did well that day. I'm not sure that it 
helped me make appropriate changes. While I know that there is always room for improvement, I often felt that I handle the situations properly. If there were any changes, it would be that I realized I needed to make a stronger emphasis on social emotional learning in my class.

Her response to the tool's ability to help her make appropriate changes directly correlates to the overall findings of this study. It appears this tool was just the first step in noticing and addressing bias, creating space for an important first step towards awareness. As these case studies reveal, awareness of bias is an important step, but not necessarily sufficient for impactful change toward anti-bias teaching.

Last, she was asked what she plans to do moving forward to continue to build awareness of bias and address the issues that arise. She stated:

I don't quite remember who I learned this from, but there was a teacher who told me that they would keep a class list handy and mark off who they were able to either talk to, have a conversation with, or have some sort of meaningful interaction with for the day/week. At the end of the week, they would notice trends in who they were giving their attention to that week in order to adjust to be more equitable. I feel like this is a simplified version of the first tool that we used-EQUIP that would help us track how many times we said a students name/called on them, etc. This could be a good tool to marry with the second tool we used [IBRT] in order to provide a space for reflection and analysis in order to make appropriate changes if need be.

As noted through the data collected in this study, the next step in the revision of the IBRT needs to lead to generative action for change in practice. Although Amber does not mention how she would address issues that arise, beyond self-reflection, she does recognize that that reflection should lead to changes that might be needed.

\section{Case Study of Susan's Use of IBRT}

\section{Educational and Teaching History}


Susan, who identifies as Asian American, is a 6th-grade teacher who taught one year in general education and one year in special education. She started teaching in Fall 2018 on a short-term staff permit and received her teaching credential in January 2019. Susan attended a local, private institution for her undergraduate education and received her Bachelor of Science in Physics and Astronomy. During that time, she was a teaching assistant for lower-division astronomy courses, and her job duties included holding tutoring sessions. During that time, she realized that she really enjoyed the feeling of students understanding what she was teaching and, then, understanding concepts. At that time, she decided that she wanted to become a teacher. About 6 months after she graduated from college, she pursued work as a paraeducator at a middle school, and that is where her career started. She has spent her entire education career at the same middle school. She noted that she did not have to interview for her current 6 th grade teaching job since she was already working at the school.

\section{Initial Ideas about Bias in Teaching}

During a 1:1 interview with Susan prior to the IBRT intervention, she was asked how she defines bias. She responded by saying, "I think of it as [something] we have, but we don't know that we have". Therefore, I wanted to further explore how she thinks that bias might show up in her classroom. So, when asked the role that bias plays in her classroom, she responded by saying:

The biases I'm aware of - it has played a really interesting role in my class. I went to a very Asian school (99\%), so I have a stereotypical view Asian kids are quiet, smart, turn work in on time. I feel like I act a different way towards other students....I try to be open-minded. The way 
that I was brought up and the way that my time in education and how I saw my classmates has played a huge part. You could call it bias, but I find myself saying/acting different ways towards different students, based on what I think I know about them.

What is interesting is that Susan's response alludes to how our lived experiences have the potential to impact the ways we view others. As a result, she knew that she wanted to be conscious of her biases during the planning and execution of her lessons. One way she was attempting to do that, prior to her participation in this study, was in trying to reflect upon the "why" behind her actions. She gave one example of how she reflected upon her biases during the planning of a science lesson. She says:

When I met up with a coworker to plan for science, we looked at what we were asking students to do and thought about what they would struggle with and why we thought that was. I think we should think about the why behind everything we are doing. In planning, think about the reason why you are saying this thing, planning this activity, how we think a student might respond and how I might respond to his response. Why am I saying this to him? Is it because I think a certain way about him? Because I'm frustrated? Because I think he could excel and he's not? Think of different responses I have and why. I think I know which barriers my students might fall into? Is my response based on how I think of them and their barrier?

Her proactive disposition towards reflection created a strong foundation for appraising the biases in her teaching practice, even before engaging with the IBRT. What she notes above confirms that reflection compels teachers to critically appraise themselves, their beliefs and attitudes and their relationship between themselves and their students (Boud, Keogh and Walker, 1985; Lange, 1990). 
When Susan first began to take on issues of implicit bias in her teaching practice, via the Equip platform, she, too, made some interesting observations.

After asking her to reflect on one of her recorded lessons, she was asked what she noticed. She responded by saying:

In watching some of the video, I noticed that I called on students who I think would know the answer and students who I think could articulate it. One of my students has a speech impediment and I don't want other kids to make fun of him. I don't know if they will. In the past they haven't but I don't know why I think that. I feel bad.

Therefore, I was curious to find out how her analysis would tie into next steps.

She said:

I'm focused on participation and who I'm calling on and how I'm responding to share outs. For my next steps, I really want to try thinking about: How do I increase the participation of my class? Right now, the same kids are participating and I'm calling on the same ones. If the whole class participates, I want to see who I'm calling on, what they are saying, how long they talk for and how I respond to them.

Susan's robust reflection prior to engaging with the IBRT closely align to the three themes that emerged from her use of the tool.

\section{Susan's Analysis of Bias in Her Teaching Practice using IBRT}

Susan completed the 6 weeks of the requested 8 reflections using the IBRT. In doing this, she was able to make some insightful deductions about the role bias plays in her teaching practice. However, a serious limiting factor to note is that three of her entries were completed on the same day, 10/12/2019. As a result, it is impossible to analyze Susan's data for convincing evidence of change and growth over the eight-week period. Nevertheless, themes do emerge regarding what Susan notices about students and how 
she thinks about the role of bias in her practice. The key themes that emerged from analysis of her IBRT-assisted reflections were:

- Perceived awareness of her assumptions

- Deficit characterization of students' behavior

- Providing supports to support students' positive engagement

Table 7

Summary of Susan's Observations Using the IBRT

\begin{tabular}{|c|c|c|}
\hline $\begin{array}{l}\text { Date/Observation } \\
\text { Number }\end{array}$ & $\begin{array}{l}\text { Summary what the student } \\
\text { said or did that was } \\
\text { noticed/addressed (IBRT } \\
\text { Question \#3) }\end{array}$ & $\begin{array}{l}\text { Emergent Themes for } \\
\text { this Date }\end{array}$ \\
\hline 9/9/2019 - \#1 & $\begin{array}{l}\text { Susan describes a student who is } \\
\text { making seal noises in class, } \\
\text { during her instruction. She then } \\
\text { explains how the student is } \\
\text { trying to coerce other students to } \\
\text { make the noises. She also } \\
\text { comments on how he blurts out } \\
\text { during independent work time, } \\
\text { instead of raising his hand, and } \\
\text { tapped his feet and pencil during } \\
\text { direct instruction. }\end{array}$ & $\begin{array}{l}\text { - Perceived } \\
\text { awareness of her } \\
\text { assumptions } \\
\text { - Deficit } \\
\text { characterization of } \\
\text { students' behavior } \\
\text { - Providing supports } \\
\text { to support } \\
\text { students' positive } \\
\text { engagement }\end{array}$ \\
\hline 9/17/2019 - \#2 & $\begin{array}{l}\text { She explains that during the Do } \\
\text { Now debrief a student turned } \\
\text { around to talk to another student } \\
\text { and, during online work time, } \\
\text { that same student tried to engage } \\
\text { his partners in a conversation } \\
\text { multiple times. }\end{array}$ & $\begin{array}{l}\text { - Perceived } \\
\text { awareness of her } \\
\text { assumptions } \\
\text { - Deficit } \\
\text { characterization of } \\
\text { students' behavior } \\
\text { - Providing supports } \\
\text { to support } \\
\text { students' positive } \\
\text { engagement }\end{array}$ \\
\hline
\end{tabular}




\begin{tabular}{|c|c|c|}
\hline 10/12/2019 - \#3 & $\begin{array}{l}\text { She explains how a student made } \\
\text { popping noises with his mouth } \\
\text { and singing "Baby Shark" during } \\
\text { independent work time. } \\
\text { He then shouted out answers and } \\
\text { talked over other students when } \\
\text { they were called on. } \\
\text { Lastly, he stood in front of the } \\
\text { projector and blocked the image } \\
\text { so no one could see him. }\end{array}$ & $\begin{array}{l}\text { - Perceived } \\
\text { awareness of her } \\
\text { assumptions } \\
\text { - Deficit } \\
\text { characterization of } \\
\text { students' behavior } \\
\text { - Providing supports } \\
\text { to support } \\
\text { students' positive } \\
\text { engagement }\end{array}$ \\
\hline 10/12/2019 - \#4 & $\begin{array}{l}\text { She explains how a student } \\
\text { walks into Science late, takes out } \\
\text { gummy bears instead of his work } \\
\text { and, then, when asked about his } \\
\text { work, he replies that he lost it. } \\
\text { He refuses to do work and then } \\
\text { falls asleep for } 15 \text { minutes even } \\
\text { after her poking him every few } \\
\text { minutes. He missed the entire } \\
\text { project launch and debrief. }\end{array}$ & $\begin{array}{l}\text { - Perceived } \\
\text { awareness of her } \\
\text { assumptions } \\
\text { - Deficit } \\
\text { characterization of } \\
\text { students' behavior } \\
\text { - Providing supports } \\
\text { to support } \\
\text { students' positive } \\
\text { engagement }\end{array}$ \\
\hline 10/12/2019 - \#5 & $\begin{array}{l}\text { A student comes into Science } \\
\text { saying something (she couldn't } \\
\text { remember exactly what was said, } \\
\text { but said it was loud and uncalled } \\
\text { for). Then, he takes out food to } \\
\text { eat, crumples up his paper and } \\
\text { walks out of Science, while } \\
\text { saying something in a weird } \\
\text { voice and singing. }\end{array}$ & $\begin{array}{l}\text { - Perceived } \\
\text { awareness of her } \\
\text { assumptions } \\
\text { - Deficit } \\
\text { characterization of } \\
\text { students' behavior }\end{array}$ \\
\hline 11/9/2019 - \#6 & $\begin{array}{l}\text { She explains that a student is } \\
\text { sleeping. When she shook her } \\
\text { awake the student yelled, "Oh } \\
\text { my god, all these teachers keep } \\
\text { interrupting my sleep!" It turned } \\
\text { out that the intern teacher from } \\
\text { USF also tried to wake her up } \\
\text { and then Susan woke her up. } \\
\text { Susan then sent the student to the } \\
\text { assistant principal's office where }\end{array}$ & $\begin{array}{l}\text { - Perceived } \\
\text { awareness of her } \\
\text { assumptions } \\
\text { - Deficit } \\
\text { characterization of } \\
\text { students' behavior }\end{array}$ \\
\hline
\end{tabular}


she completed a reflection (a sheet of paper basically that has student reflect on their behavior) and return to class.

Overall, Susan's reflections tended to largely focus on showing an awareness of her assumptions, with less description of actual actions or interventions in the classroom. Providing supports to encourage positive behaviors does emerge as a theme, but to a lesser extent. This attempted positive approach is sometimes counterbalanced by descriptions that include deficit characterizations of students' actions. However, a larger part of her reflection demonstrates that she is aware of the assumptions that drive those characterizations. As such, it appears as though her reflections drive a large part of her realizations.

\section{Theme 1: Perceived Awareness of her Assumptions}

An enlightening part of Susan's IBRT reflections is that there were ten instances where she showed a perceived awareness of her assumptions, despite some of the challenges she shows with understanding and supporting some of her students' decisions. In particular, she reflects on how children's race, ethnicity, and/or background may influence her perceptions. For example, she notes things such as:

- "Isaac is Korean-American (adopted) and I think I expect him to act a certain way because of my own perceptions of how Asian students act and my own experience going to a Chinese immersion school and how I was told to behave in class" 
- "Brooklyn is an African American boy and comes from a middle class family. I feel like I'm holding him to higher expectations because he comes from a more "solid" household. I feel like he should know better because his home life is more stable. It doesn't actually make much sense"

- "Damien is an African American boy with an IEP. His mother is a preschool teacher and seems to be middle class. He also has a sister that goes to our school too. From what I've gathered, it's just the two of them and mom. I'm not sure if the dad is in the picture. And as I've said before, I keep gravitating towards the boys in my class and boys with needs. Isaac and Brooklyn who I've talked about before have learning needs. Isaac may be getting assessed for ADHD and Brooklyn has an IEP and has been diagnosed with ADHD”

- "Zed has an IEP for emotional disturbance and actually has a 1-1 para. He is a white male. He lives with his grandmother (who was actually my teacher in high school) and grandfather because his mother is in jail for drug charges. He's a very sweet boy but has a lot of trauma, from what I can see. And again, he's another male with a learning need. Perhaps there's some sort of biases with male children and learning needs?”

- "Alani is a female student and African American with an IEP. I worry because all the students that are standing out to me seem to have IEPs or need an IEP (e.g., Isaac). I wonder if there's some sort of bias I have with students with IEPs??” 
- "It assumes that this student is lazy (I don't like using that word) and disrespectful"

The dichotomy of Susan's awareness of her assumptions and her limited (reported) actions to counteract these indicates that while she is aware of her biases, she is not yet able to directly apply this awareness to changes in practice. Although the data does not appear to chronicle many of the supports implemented, her reflections do seem to give her insight into what she could have done/could do to support different outcomes moving forward. She says:

- "I definitely could have asked Isaac what he needed from me or what support he needed during the activity. I could have addressed Isaac's needs first before immediately moving towards reprimanding him"

- "Knowing Brooklyn has an IEP and knowing his goals, I should have offered him breaks or checked in with him to see what he needed"

- "I actually wish I could've sat down with Isaac and talked through what was going on. After meeting with his mom, I found he's harboring a lot of trauma and guilt over his parents' divorce. Getting to know this part of Isaac would've been extremely helpful"

- "I could've offered Damien a break in the classroom to keep him awake or given him a better snack than the gummy worms he brought. The coming to class late piece is a little trickier to solve so I'll have to think about that one a bit more" 
Conversely, in retrospect, although she appears to be aware that assumptions drive her opinions of appropriate behavior, like Amber, she does not yet go as far as to mention how her views inform what she considers to be appropriate and inappropriate.

Susan's open discussion of how bias may be impacting how she views children's behavior in the classroom gives some hope that continued reflection using a supportive tool such as the IBRT could lead to more concrete changes in practice over time. However, it is important to note that while incorporating individual strategies to remediate bias are necessary to interrupt the impact of bias, alone they are not sufficient for creating the long-term change needed to create equitable change for students (Gullo, Capatosto \& Staats, 2019). I will discuss this possible implication more thoroughly in Chapter 5.

\section{Theme 2: Deficit Characterization of Students' Behavior}

Unlike Amber, there were six instances, where Susan's written reflections demonstrated a deficit characterization of students' behavior. This thematic category was one of the less prevalent themes in her reflection, whereas providing supports and having a perceived awareness of her assumptions were more prevalent for her; however, its appearance 6 times across the 6 reflections is notable. I coded a description as using a deficit characterization if the teacher 1) named a behavior that she saw as negative/ undesirable AND 2) provided a presumed explanation for the behavior that referred to a perceived weakness in the child. For instance, when describing students she felt did not 
want to do work, or behaved in what she perceived as a distracting manor, she made statements such as the following, [text coded for deficit characterization in italics]:

- "This afternoon in math class, Brooklyn continuously turned around to talk to other students and talked while I gave instruction. Brooklyn narrates a lot of what he's doing and is very vocally expressive. As a side note, he's been diagnosed with ADHD and has an IEP"

- "Isaac has been on my radar for a few weeks. His behavior has gotten increasingly inappropriate and extremely disruptive. He has been whining, calling out, making popping noises, moaning, standing in front of the projector, singing, etc. Isaac is bright and knows the expectations of the classroom but refuses to follow them. And so far, even after meeting with his mother, nothing really motivates him"

- "More recently, Zed has been coming to class loud and disruptive the peace. He will come in and say the most ridiculous things and frankly, quite inappropriate. He will take his seat and try to get started but will continue calling out" It appears Susan's deficit characterizations of students' behavior stem from her expectations of what their comportment should be in a classroom setting and her assumptions that not meeting those expectations come from weakness on the part of the child. For example, in Observation 1 she says, "Brooklyn continuously turned around to talk to other students and talked while I gave instruction"- right or wrong - implying that her voice should hold power in the classroom space. Similarly, in Observation 2, she 
states, "Isaac is bright and knows the expectations of the classroom but refuses to follow them". Although it is unknown who created and determined the expectations of the classroom, it appears that her ideas of how it should operate is often compromised by the students, and she sometimes searches for reasons for this mismatch that place responsibility on the student rather than on the teacher and/ or teaching environment. “Call 'that one student' what you will: challenge, EBD, troublemaker, the one who needs more time; but the moment he or she has a label, chances are bias will follow" ((Gullo, Capatosto \& Staats, 2019).

\section{Theme 3: Providing Supports for Students' Positive Engagement.}

In Susan's reflection she appeared to have remained conscientious of what might be needed to promote students' positive engagement and interaction. Although she made a lot of judgements about their behaviors, and the majority of these were negatively characterized (e.g. assuming a child was "unmotivated,"), she did indicate some instances where she attempted to support the behaviors that she wanted her students to exhibit, or acknowledging what she could have done to help them achieve her expectations. Ten instances in her reflections were coded as providing positive supports to uphold her preferred behaviors. For example, she notes things such as:

- “...Isaac tends to need to fidget so I have given him pipe cleaners to fidget with during class"

- "Isaac benefits from fidgets and silly seats sometimes so if he asks appropriately, he will get to use them" 
In addition, some reflections imply positive supports without directly naming a supportive action. For example, “...He needs organizational support so I feel bad faulting him about his homework."

Based on her IBRT reflections, her preferred student behaviors were for them to: sit in their seat, raise their hand, not talk during class time, follow classroom expectations, ask for support when needed, come to class on time, immediately take out work, walk into the classroom quietly, etc. In fact, throughout the analysis of her data, she made 19 references to the supports that she provided that were aligned with promoting her preferred behaviors. However, it is difficult to determine if she offered an equal ratio of supports to expectations. She noted doing things such as: providing a fidgeting device, offering a silly seat, etc. However, in comparison to Amber, it appears that she does not name many of the things that she did to promote her preferred behaviors.

Throughout Susan's reflection in the study, it appears as though her characterization of students' behavior was in relation to her desired behaviors, which, similarly to Amber's, were consistently described as being non-distracting. For example, the quotes below describe the behavior she would like to see from her students:

- "I would prefer Isaac to be sitting in his seat and raising his hand if he has a question"

- "The only problematic part was that Brooklyn was talking while I was talking and not following class expectations during work time" 
- "All of Isaac's behavior is problematic and the preferred behavior is that he follows expectations and ask for support when he needs it” The interesting part of Susan's quest to provide supports for students' positive engagement is that she appears to be aware of some of the biases around her perception of their ability to live up to her expectations. However, she names few supports that she provides that will help students to do so.

\section{Susan's Reflection on use of IBRT}

One of the most interesting aspects of this study is understanding how or if teachers gleaned new insights into their biases, using the IBRT. A better understanding of how or if it allowed them to become more aware of their biases gives me, as the researcher, further insight into how this tool can be amended and further developed.

When asked about her interactions with the tool, Susan responded,

I found it interesting that each week I focused on the same or similar students. All the students I chose were students that displayed some sort of deregulation or unexpected classroom behaviors. And I believe most of the students that I wrote about had IEPs or needed to be assessed. It was helpful for me because it opened my eyes to what I was paying attention to and what I could be doing differently. It also helped me realize that I wasn't focusing on my other students as much as the students I was writing about. It was almost if I was constantly watching them and waiting for them to do something because it's like I knew they would do something sooner or later. I think it was helpful in noticing implicit bias because I was able to shift my attention to other students that really needed support and actually helped me uncover additional implicit biases. For example, I found out that I call on boys slightly more often than girls when asking a question about math or science content. Do I actually believe that boys are "better" at math and science and more likely to give a correct response? I found it interesting because I am a woman teaching both subjects and I've always advocated for more females in the STEM field. I am currently working with my mentor on equity of voice in my classroom and I have begun tracking the students I am calling on or checking in with. It's been interesting actually. And the students that I was initially 
focusing on are still somewhat of an issue for lack of a better word but through the process of identifying what I could have done differently for them, they're more responsive to me in class and actively try and be a part of the community. I am really looking forward to seeing what kind of data I collect using this tracking system for equity of voice!

Susan's response on the usefulness of the tool helps me, as the researcher, to better understand the answer to this study's research question of, "What are the impacts of a reflective tool intended to support teachers to notice and address implicit bias in their teaching practice?" The narrative helps to frame the fact that a lot of Susan's reflections stemmed from the lens of examining her own predispositions towards students.

In accordance with the literature, Friedrich, Flunger, Nagengast, Jonkmann, \& Trautwein (2014) examine how teachers' expectations affect student academic progress. Similar to stereotype threat, they examined the Pygmalion effect, which is the effect that teachers' expectations have on students' future achievement. Brophy and Good (1970) described the cycle in which the Pygmalion effect evolves. One of the steps in the cycle says that teachers' beliefs about certain students begin to lead to preferential treatment, such as providing more attention and support to students, offering more challenging learning materials, interacting with the student longer, and being more responsive to the work of students for whom they hold high expectations. Since teachers are an important factor in the formation of a student's self-concept, this preferential treatment clearly impacts children's development as learners (Friedrich et. al, 2015). Good (1987) contends that teachers' expectations can be formed for an entire class, groups of students or specific individuals, although most empirical studies focus on the individual students or 
specific groups of students, like racial minorities or those from a lower-class background (Jussim et. al, 1996). Susan's reflection on her use of the IBRT demonstrates her ability to retrospectively see the impact her concerted attention had on select students.

\section{Case Study of Anna's Use of IBRT}

\section{Educational and Teaching History}

Anna, who identifies as white, is a teacher coach, with a teaching background of 7 years. She is tasked with observing teachers and giving them feedback on their teaching practice. In this role, she helps teachers to look at and think through their data sets; talks to them about the benefits of small groups and helps them to develop lessons that target specific students' needs - i.e. interactive writing lessons that help engage struggling students. As such, she views herself as someone who helps teachers to implement authentic interactions and follow through with Student Support Teams (SST) if needed. Anna started by getting her bachelor's degree from UC Davis in History and Communications. She then went on to work in Marketing for 4 years. After that, she went to San Francisco State University to get her teaching credential. She then taught for 5 years, took a year of leave from teaching, enrolled in a Reading Certification program and, subsequently received her Master's in Education.

Anna was also a student in my course titled, "Practitioner's Based Research in the Elementary Classroom". While in that class, she sought to explore the effect of reading culturally authentic literature on a student's self-esteem. She wanted to better understand how and if students seeing their cultural representation in literature determined how they 
viewed themselves. Through her exploration of building awareness around how students do/don't see themselves in the literature, she realized that she may have incorporated a lot of bias into the analysis of her data. Therefore, I was curious about how she defined bias in the first place.

\section{Initial Ideas About Bias in Teaching}

According to Anna, bias is “....something that we all have that is really hard to control". She noticed that she has a bias towards calling students, "friend" and who she calls "friend". Because a lot of her research and career focused on building relationships with students, to draw authentic connections, she used the word "friend" to make a quick connection with kids because she is not always in their classroom. When asked why she associates the word friend with a bias, she replied, "I never say it to this kid that I don't like". Therefore, Anna's part in this study was intended to help her become more aware of her biases and how those biases could impact students.

When Anna first began to take on issues of implicit bias in her teaching practice, through the reflections she made using the Equip platform, she noticed that because she is a teacher mentor, she did not necessarily have her own specific learning goals for students. Instead, she was modeling strategies for the teacher to use. As a result of being somewhat removed from teaching herself, she was able to reflect on her teaching practice, via the Equip platform, when she went in to model lessons for the teacher she was coaching. 
While engaged with the Equip platform, Anna appeared to focus her reflection on students she thought she was engaging, through what she perceived to be culturally relevant literature. She felt that students are more engaged with literature when they feel that they are culturally represented in the story. Therefore, in reflecting on the students who stood out to her, it was those who she felt $\mathrm{did} / \mathrm{did}$ not connect to a story that tied to their culture. For example, when she read stories like "Do Like Kyla" or "Whistle for Willie" that featured African American characters, she perceived her one African American student to be most engaged. So, during the modeling of her lesson, on the Equip platform, she did not notice much of what this study's other two participants described as distracting behaviors, because she was looking to prove her philosophy correct - that as long as the student(s) could see their culture in the characters, they were “engaged". This same trend is noted in Anna's completion of the IBRT. When asked, "If any part of the student's behavior seemed problematic to you, describe the preferred behavior", she marked no or not applicable on seven out of eight of her responses.

\section{Anna's Analysis of Bias in Her Teaching Practice Using IBRT}

Anna completed the all 8 weeks of the 8-week study using the IBRT and, therefore, was able to make some insightful deductions about the role bias plays in her teaching practice. While some emergent themes were the same as those found for Amber and Susan, there are some key themes that emerged from her participation in the study that were substantially different. The themes were:

- Looking for Evidence of Cultural Connections 
- Preference for Evidence of Positive Cultural Connections

- Showing Awareness of Assumptions

One notable difference between Anna's reflections and those of Amber and Susan is that she focused much more on curricular choices and implementation. This is likely due both to being a more experienced teacher and to her role as an instructional coach. Thus, her reflections are all situated in the context of students engaging with books and her goal of using more culturally diverse books in the classroom. Within that more focused context, though, her reflections share similarities with the other participants in that, many of her themes tend to stem from a focus on students' interest/disinterest in what was being taught. This may be due to the prompts in the IBRT that ask teachers to focus on students. The things she attributes as connection points tend to be at the level of clothing, hairstyles, food etc. and she specifically attributes connection to children whose race or ethnicity match those of the characters in the books she reads to them. Table 8 , below, summarizes the things that Anna tended to talk about as it relates to what she noticed and addressed in the classroom:

Table 8

Summary of Anna's Observations Using the IBRT

\begin{tabular}{|l|l|l|}
\hline $\begin{array}{l}\text { Date/Observation } \\
\text { Number }\end{array}$ & $\begin{array}{l}\text { Summary what the student said } \\
\text { or did that was } \\
\text { noticed/addressed (IBRT } \\
\text { Question \#3) }\end{array}$ & $\begin{array}{l}\text { Emergent Themes on } \\
\text { this Date }\end{array}$ \\
\hline $9 / 9 / 2019-\# 1$ & $\begin{array}{l}\text { Anna describes a student who was } \\
\text { talking about going to Japan in } \\
\text { October and how the student said }\end{array}$ & $\begin{array}{l}\text { Looking for } \\
\text { Evidence of } \\
\text { Cultural }\end{array}$ \\
\hline
\end{tabular}




\begin{tabular}{|c|c|c|}
\hline & $\begin{array}{l}\text { that she will take a picture of } \\
\text { herself in a kimono. Anna } \\
\text { described her body posture as } \\
\text { having a straight back and open } \\
\text { body posture. She said that she } \\
\text { gave her eye contact while telling } \\
\text { her about her trip to Japan. }\end{array}$ & $\begin{array}{l}\text { Connections } \\
\text { - Preference for } \\
\text { evidence of } \\
\text { positive cultural } \\
\text { connections } \\
\text { - Showing } \\
\text { Awareness of } \\
\text { Assumptions }\end{array}$ \\
\hline 9/18/2019 - \#2 & $\begin{array}{l}\text { She describes a student who } \\
\text { "blurted out" that he had worn } \\
\text { whatever attire was } \\
\text { described/mentioned in the book } \\
\text { that she was reading. She said that } \\
\text { he made eye contact when saying } \\
\text { it and raised his hand halfway, not } \\
\text { waiting to be called on. }\end{array}$ & $\begin{array}{l}\text { Looking for } \\
\text { Evidence of } \\
\text { Cultural } \\
\text { Connections } \\
\text { Showing } \\
\text { Awareness of } \\
\text { Assumptions }\end{array}$ \\
\hline 9/25/2019 - \#3 & $\begin{array}{l}\text { She describes a student who waved } \\
\text { her hair making her barettes clack } \\
\text { as she read a book. She said that } \\
\text { this student kept focus on the book } \\
\text { and displayed eye contact and a } \\
\text { huge smile while Anna was } \\
\text { reading. }\end{array}$ & $\begin{array}{l}\text { Looking for } \\
\text { Evidence of } \\
\text { Cultural } \\
\text { Connections } \\
\text { - Showing } \\
\text { Awareness of } \\
\text { Assumptions }\end{array}$ \\
\hline 10/3/2019 - \#4 & $\begin{array}{l}\text { She describes a student who sat } \\
\text { quietly, giving her eye contact and } \\
\text { leaning towards her. She said that } \\
\text { the student did not speak in whole } \\
\text { class discussion, but smiled largely } \\
\text { at the end of the story and showed } \\
\text { an enthusiastic thumbs up when } \\
\text { asked how she liked the story. }\end{array}$ & 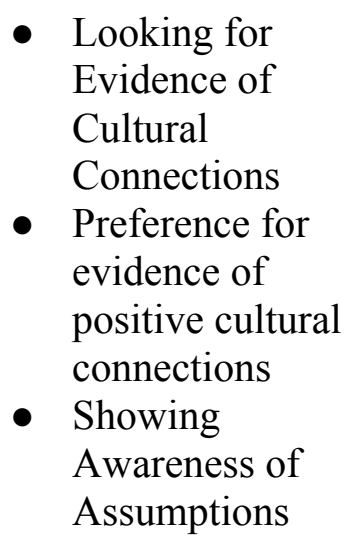 \\
\hline 10/24/2019 - \#5 & $\begin{array}{l}\text { She describes a student who gave } \\
\text { eye contact, had engaged body } \\
\text { language, but said they disliked the } \\
\text { story when she responded to a text }\end{array}$ & $\begin{array}{l}\text { - Looking for } \\
\text { Evidence of } \\
\text { Cultural } \\
\text { Connections }\end{array}$ \\
\hline
\end{tabular}




\begin{tabular}{|c|c|c|}
\hline & survey. & $\begin{array}{l}\text { Preference for } \\
\text { evidence of } \\
\text { positive cultural } \\
\text { connections } \\
\text { - Showing } \\
\text { Awareness of } \\
\text { Assumptions }\end{array}$ \\
\hline 10/31/2019 - \#6 & $\begin{array}{l}\text { She talks about a student who sat } \\
\text { on her hands while sitting in a } \\
\text { chair, gave full eye contact and } \\
\text { smiled shyly while they talked. } \\
\text { The student said, I eat Dim Sum } \\
\text { with my poa poa (SP?) so I liked } \\
\text { that story. I also like adventure } \\
\text { stories and the other one was an } \\
\text { adventure story". }\end{array}$ & 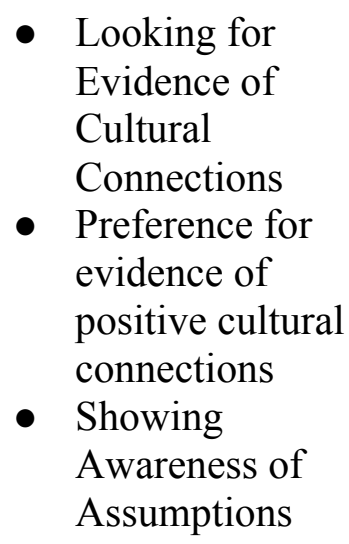 \\
\hline 11/10/2019 - \#7 & $\begin{array}{l}\text { She notices a student who was } \\
\text { yelling, crying, throwing things } \\
\text { and was hard to understand } \\
\text { because of his "emotional" } \\
\text { response. }\end{array}$ & $\begin{array}{l}\text { Looking for } \\
\text { Evidence of } \\
\text { Cultural } \\
\text { Connections } \\
\text { - Showing } \\
\text { Awareness of } \\
\text { Assumptions }\end{array}$ \\
\hline 11/10/2019 - \#8 & $\begin{array}{l}\text { She talks about a student who was } \\
\text { excited to share about her } \\
\text { grandma. The student told her he } \\
\text { was just american. } \\
\text { She described her as being } \\
\text { engaged and talkative during her } \\
\text { read aloud. }\end{array}$ & 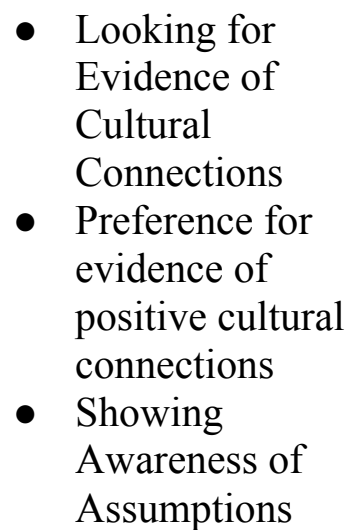 \\
\hline
\end{tabular}


Overall, Anna's reflections tended to focus on describing students who she perceived to be engaged with the stories she read to the class. In fact, the largest theme for her is Looking for Evidence of Cultural Connections. Some of the codes that emerged to help draw this conclusion are actually counter to the largest themes in Susan's - who often described deficit characterizations of students' actions. Anna’s description of student actions emerged as codes like: Talkative, Very kind, Good friend, Hilarious, Perceived engagement. These codes emerged largely within the context of how she felt students received what she thought was culturally relevant content.

\section{Theme 1: Looking for Evidence of Cultural Connections}

This theme happens to be the most prevalent theme for Anna. In fact, she made 17 references to cultural connotations and implications throughout her 8 weeks. Some of the quotes that describe her characterization of students making cultural connections are:

- "I also assumed that she would want to help me pronounce Spanish words, but that did not happen. I could make assumptions why, but I will resist"

- "I made assumptions that Stella would enjoy more books that I read and I did not at all think about the genre of the story..."

- "Maddy, who clearly has some Asian heritage, always said she was from San Francisco",

The quotes are just a few of the ways in which Anna attempted to associate cultural literature to a student's cultural connection. It appears Anna's assumptions about students' interests stem from her expectations of how they might connect with certain 
types of literature. She notes positive expectations and evidence of how students provided evidence of meeting these expectations. For example, in a reflection after reading [describe topic of book/ cultural setting] Anna notes:

I was hoping that Miyabi would be excited to participate in the lesson. Her first name is "Alyssa," but last week she told her parents she wanted to go by her Japanese middle name, Miyabi. Therefore, she goes by "Miyabi" now. I made the assumption that she was eager to learn/share more about her connection to her Japanese culture

As shown in this example, Anna is excited to envision the ways in which students might connect to the literature she has chosen. She seems to choose books with the cultural backgrounds of her students in mind. In her written reflections, her definition of culture focused on features such as names, clothing, food, and other surface-level markers of culture.

Anna's reflections indicate that she is working to build positive cultural connections for students in her class. Her actions indicate a focus on "cultural match", meaning she assumes that children who match the ethnicity of a book character will best connect with/ benefit from the book. This may indicate a "positive bias" of sorts, where she assumes a positive reaction of a certain group of students. Much like the Pygmalion effect, this assumption may predispose her to over-notice or over-attribute cultural connection for the children she assumes will have it. That said, her intentional work to broaden who is represented in the books used in the classroom indicates awareness of the bias that exists in how teachers select and use classroom literature.

\section{Theme 2: Preference for Evidence of Positive Cultural Connections}


Perhaps because Anna anticipated that students would respond positively in situations where she thought culturally relevant content was presented, and she devoted significant work to selecting books that she hoped would connect with students' cultural contexts, her reflections sometimes indicated that she was troubled when students did not connect in the way she hoped. This formed a consistent theme across her reflections. There are 12 references in which she describes surprise or uncertainty when students reacted differently than she anticipated. For example, she notes:

When I was stumbling on how to pronounce a word in Spanish I looked to Delilah for help, but she sat quietly. At the end of the story I asked for a reaction, thumbs up, down, in the middle. She gave it a large thumbs up with a giant smile across her face. I was happy to see this reaction, but a little surprised since she was so stoic and quiet during the reading

After going through her students' surveys for connection to text, she realized that her student, Stella, did not like any of the stories she read. Stella is Chinese American and reported "dislike" for every book. That week, when reading, Anna focused on watching her during the read aloud to see if her behavior could show her any signs of her response to the text. Anna notes,

...After the read aloud, she again filled out the response to text survey and "disliked" the story. I am wondering why she is responding this way. Is it connected to the cultural unit? Or does she not like me? Or does she find story time boring? Or is she just randomly responding? I plan to talk to her about it next week in an interview

At the end of the unit, according to the questionnaire, Stella only "like" two books, Dim Sum for Everyone and Grandfather's Journey. Therefore, Anna was interested to understand why and says: 
I interviewed Stella to further understand her reported "dislike" for a majority of the stories I read to the class. At the end of the unit, according to the questionnaire, she only "like" two books, Dim Sum for Everyone and Grandfather's Journey. I was interested to understand why

In Anna's estimation, she was reading books that she felt students should have connected to, according to her perception of the characters' similarities to her students' cultures. She says"

All year I have been teaching about culturally relevant literature. I have tried to connect students to the cultures their family identifies with. Maddy, who clearly has some Asian heritage, always said she was from San Francisco. So I left it at that. Today, when I read Dim Sum for Everyone, she talked about how her grandma, who only speaks Chinese, likes to take her to Dim Sum on Sundays. After this exchange whole class, I pulled Maddy aside and said, "wait, so you have family from China and San Francisco, are you Chinese American?" And Maddy said, "Nope, just San Francisco. I am just American." I said okay, and left it at that

The interesting part of Anna's second most prevalent theme is that a lot of her reactions stem from her attempts to engage students in the cultural literature that she assumes they identify. When she does not get the reaction that she expects, the IBRT probes her in a way that helps her to reveal the assumptions that she made. In the beginning of the study, Anna mentioned how she makes attempts to create authentic connections with students and, from these examples, she tries to enhance her rapport with them through what she considers to be culturally relevant literature. It appears that use of the IBRT may be pushing her to examine her assumptions and to notice points of mismatch between what she assumes and ways in which students do or do not connect with the literature as anticipated. When things do not go as planned, she leans into her curiosity and shows an awareness of her assumptions, which leads to the third theme. 


\section{Theme 3: Showing Awareness of Assumptions}

An enlightening part of Anna's IBRT reflections is that there were seven instances where she showed awareness of her assumptions as she worked to unpack disparities between what she anticipated and how students responded to the books and instructional activities she chose. In particular, she reflects on how her perception of a student's ethnicity and/or background may influence her perceptions. Examples include (italics indicate awareness of assumptions):

I was hoping that Miyabi would be excited to participate in the lesson. Her first name is "Alyssa," but last week she told her parents she wanted to go by her Japanese middle name, Miyabi. Therefore, she goes by "Miyabi" now. I made the assumption that she was eager to learn/share more about her connection to her Japanese culture

Anna assumed that because she read a book with a character with the same heritage as her student, her student would like the book. She notes:

I made the assumption that she would enjoy the book since the main character was just like her. However, that was true in this instance. Her mom even approached me the next day to let me know how much she talked about the story when she went home

While the first two examples show examples of potentially positive assumptions, she also reflects on times when her assumptions may get in the way of understanding student experiences. For instance, she explicitly says:

HUGE assumption made here. Just because this story is about paletas and living in a Latinx barrio does not mean that Delilah has had similar experiences like the characters. I also assumed she would want to help me pronounce Spanish words, but that did not happen. I could make assumptions why, but I will resist 
Similarly, when a student did not connect with the story, according to Anna's expectations, she tended to attribute it to the student not paying attention. Anna says"

I think my bias in grounded in the assumption that because she did not like my story, she was not engaged in storytime! When I noticed she did not like any of the books I read, I assumed that meant she was not every paying attention. But I witnessed her paying attention, therefore that was a bias assumption, right?

Anna began to realize that students did not necessarily connect with stories that she thought were culturally relevant, rather it was possible for them to connect based on genre. She notes:

I assumed that since Stella was Chinese American, she would most likely enjoy the books that connected with her identified culture. However, she only like the Dim Sum book (which did connect to her culture), but also Grandfather's Journey, which is about a Japanese man traveling to America. Stella informed me she really likes adventure stories, and that played a major impact on why she would like/dislike a story

Like Susan, the dichotomy of Anna's awareness of her assumptions and her limited (reported) actions to counteract these indicates that while she is aware of her biases, she is not still working to directly apply this awareness to changes in practice. The data does not appear to chronicle many of the supports implemented and her reflections only seem to note what she could not "assume" moving forward. She does not mention any changes that she would make to instructional content or her personal interactions, making it difficult to determine how she might make changes to her teaching practice moving forward. Another important thing to note is that because Anna is a Coach, her failure to mention instructional changes that she would implement, herself, most likely means that it would impact her ability to effectively Coach and mentor other teachers around 
instructional changes that they should make in light of their biases. This cycle of awareness has not necessarily correlated to changes in instructional practice, which means that the IBRT is just a first step to addressing the topic of bias.

\section{Anna's reflection on use of IBRT}

Anna's responses to her take on the usefulness of the IBRT appears to focus on the value that she found in being compelled to reflect on her actions and her teaching practice. When asked the ways she found the IBRT to be helpful, she responded by saying:

It was helpful to have a space to be reflective about my teaching. Being a reflective teacher is one of the greatest ways we can grow in our practice, however in our busy schedules we rarely have the time to do this. The tool forced me to sit down and think deeply about one interaction in the day and how my words/actions/biases could have impacted my teaching process

As stated in Chapter 2, using critical reflection as a tool for teacher growth allows teachers to pay attention on purpose. Authors Cimer, Cimer \& Vekli (2013) found that reflection increases greater self-awareness and can lead to change in practice. Day (2001) also argues that teacher reflection is necessary for the improvement of practice.

Reflection compels teachers to critically appraise themselves, their beliefs and attitudes and their relationship between themselves and their students (Boud, Keogh and Walker, 1985; Lange, 1990). To extend the argument, critical self-reflection is questioning the broader structures of society - an ability to stand outside of their practice and see what they do from a wider perspective. 
Although, during the interview, Anna did not list any specific instances where she found the tool to be helpful, she did acknowledge that it may have helped her on a more subconscious level. Therefore, when asked what she plans to do moving forward to continue to build awareness of bias and address the issues that arise, she stated:

I think continuing to reflect upon my interactions with students and the way I approach teaching is key. I need to remember the different stories we bring into the classroom and the impact that can have on students (or I) throughout the day. I will definitely try to continue this work and understanding the biases I bring into the classroom and how that shapes my teaching practice. I am grateful for this experience

While her response gives me hope that she will attempt to be more conscientious of her biases, it demonstrates that identification of potential bias is only a first step. While the case study teachers seemed very willing to consider their own biases and reflect on how they might be impacting instruction, there were few instances where teachers reported change in practice as a result.

\section{Conclusion}

The case studies chronicled above show promise in the IBRT's ability to create the space that teachers need to become in-tune to their biases. As all the teachers demonstrated, they were able to name, notice and reflect upon bias in a way that led them to look introspectively. Although the IBRT showed promise in helping these teachers to examine their interactions with named students, the data from this study does not suggest that their/an awareness to bias is enough to lead to changes in practice. In addition, the biases that participants named and reflected upon appeared to fall into specific categories based on the participants' perspective (for instance, bias based on knowledge of 
children's home situation), but they rarely took up bias based specifically on race, despite the large negative impact of racial bias on children's school experience. The final chapter of this study will examine how the findings from these case studies are connected to the literature on both bias and educational change and explore how those connections lead to implications for leadership policy to move toward more anti-biased teaching. 


\section{Chapter 5: Implications and Recommendations}

The goal of this study was to create a tool that allowed teachers to reflect on how their implicit biases impacted their teaching practice in regard to the range of students in their classroom. Therefore, this study sought to understand:

- What are the impacts of a reflective tool intended to support teachers to notice and address implicit bias in their teaching practice?

As stated in Chapter 2, the topic of implicit bias is an abstract concept. Because its impacts are byproducts of something that may not be "seen," research shows that this invisible construct has detrimental effects on the academic outcomes of minority students. As such, this study sought to examine how reflection can prompt teachers to think about their biases in a way that could, potentially, lead to generative change. By virtue of bias's invisibility, it is important to understand how it shows itself in teaching so that it can be identified and named. The results of this study show, however, that naming is a necessary first step of this process but does not by itself lead to changes in practice.

The findings of this study indicate that the IBRT as a support for meaningful reflection was just the first step in noticing and addressing bias, creating a space for awareness that seemed to feel comfortable enough for participants to name and explore potential bias. As these case studies reveal, awareness of bias is an important step, but not necessarily enough for impactful change toward anti-bias teaching. In the preceding sections, I will summarize insights gained from the three case studies presented in Chapter 4, link these findings to the existing literature on implicit bias in teaching, and 
discuss implications for educational leadership and policy to support reducing the negative impacts of bias in the classroom.

\section{Interpretation and Synthesis of Findings}

There are several ways that the IBRT proved to be useful in helping teachers to reflect upon their biases. However, one of the biggest lessons learned, through the implementation of this study, is that the identification of potential bias is not enough to lead to action. The analysis, as summarized and interpreted below, indicates that participants were able to sharpen the lens through which they saw students, but it does not appear that the IBRT caused them to make explicit changes or to challenge these lenses in a sustained way. Therefore, in that way, the IBRT needs to be refined and expanded to support changes in teacher action, based on the biases that are identified via the IBRT.

\section{Case Study Teachers Were Able to Identify Potential Biases}

Per the results of this study, it appears as though the teachers were able to identify some potential biases using the IBRT prompts. As discussed in Chapter 2, using critical reflection as a tool for teacher growth allows teachers to pay attention on purpose. Authors Cimer, Cimer \& Vekli (2013) found that reflection increases greater selfawareness and can lead to change in practice. Day (2001) also argues that teacher reflection is necessary for the improvement of practice. Reflection compels teachers to critically appraise themselves, their beliefs and attitudes and their relationship between themselves and their students (Boud, Keogh and Walker, 1985; Lange, 1990). To extend 
the argument, critical self-reflection is questioning the broader structures of society - an ability to stand outside of their practice and see what they do from a wider perspective. It also allows them to see how the dynamics of power are at play in their practice (Nicholas, Tippins, and Wiesemen, 1997).

There are several ways that the case study teachers demonstrated critical selfreflection and identifying ways in which bias might impact their assumptions and actions. First, the tool prompted them to consider how bias might play a role in what they noticed/ how they responded, and case study teachers all showed that they were willing and able to reflect on this. For example, the tool specifically asks the teachers to "Find one way in which bias might be informing your interpretation? Consider the student's race, class, gender, language, etc". The responses varied, but tall case study teachers identified times or instances in which bias might account for how they saw or responded to a situation.

While some of the responses to this prompt seemed to dodge reflection on potential negative impacts of bias, other instances indicated that participants were both willing and able to consider how implicit bias might impact who and what they notice in the classroom, for instance, when Anna reflected:

I had a bias of this being a 'normal' behavior for him, so I did not immediately try to find out the root for the behavior which should actually have consequences for the other student who poked him with a pencil.

While all the participants were able to reflect on potential biases in how they saw and interpreted students' actions, each case study teacher's working definition of bias 
differed, thus impacting what they focused on in their reflections. For example, Amber's identification of potential bias dealt with assumptions regarding students' home lives and perceived ability, with no mention of race across any of her reflections, despite teaching in a multi-racial class.

Susan's identified potential biases, on the other hand, were primarily focused on assumptions she knew she made based on children's race, culture and, sometimes, gender. Interestingly, while Susan's reflections mentioned race quite a bit, she seemed most comfortable reflecting on potential bias regarding students in her own racial group (Asian American). She seemed particularly aware of how her own internalization of the "model minority myth" (which she describes but does not name as such) and her own educational history might impact her expectations of Asian American students. She mentions the race of other students in her reflections but there were no instances of reflecting on potential racial bias regarding children from other racial groups.

Anna's strong focus on literacy and cultural connection through books seemed to influence her to identify potential bias in terms of perceived "cultural match" between instructional activities and children's lives. Anna came into this research project in the middle of her own research, examining the impact of using more culturally diverse children's books on how children interact with literacy activities. All her reflections indicated this focus. As such, her working definition of bias during the time period of the study was likely more focused on "cultural match" than it might have been at other time 
points. Nonetheless, the consistency of her reflections indicates that she identified and interpreted instances of potential bias through this lens.

The variation with which the case study teachers identified potential bias in their practice is indicative of the fact that bias was noticed according to participants' individual definitions of what bias meant to them. As Evelyn Carter (2017) notes, "Bias is woven through culture like a silver cord woven through cloth. In some lights, it's brightly visible. In others, it's hard to distinguish." In this way, the IBRT shows promise in helping teachers identify and reflect on something that is often hard to "see," and the fact that it allowed teachers with wide ranging working definitions of bias to meaningfully reflect on their practice shows promise for broader implementation. This also points to the challenge of using such an open and individualized tool to support change toward anti-bias teaching practice.

\section{Identification of Potential Bias Is Only a First Step}

While the case study teachers seemed very willing to consider their own biases and reflect on how they might be impacting instruction, there were few instances where teachers reported change in practice as a result. This may well have to do with the short time frame of this initial study, but it is also an issue to consider in developing a more robust professional learning program to identify and address implicit bias. As stated in Chapter 4, Susan's awareness of her assumptions and her limited (reported) actions to counteract these indicates that while she is aware of her biases she is not yet able to directly apply this awareness to changes in practice. Although the data does not appear to 
chronicle many of the supports implemented, her reflections do seem to give her insight into what she could have done/could do to support different outcomes moving forward. Her assertion of "could have" and "should have" statements indicate that there is potential for Susan to apply her new insights to change how she responds to similar situations in the future. Given the challenge of making substantive changes to practice, a focus of a revised and expanded IBRT needs to be prompting and supporting positive anti-bias action as a result of insights from the reflection.

Additionally, like Susan, Anna's data does not chronicle planned or enacted changes based on prior reflections, and her reflections only seem to note what she could not "assume" moving forward. She does not mention any changes that she would make to instructional content or her personal interactions, making it difficult to determine how she might make changes to her teaching practice moving forward. Anna's use of the tool is further indication that one limitation of the tool as developed is the focus on bias identification. A full professional learning model using the IBRT as a starting point would also need to focus on productive action.

Lastly, Amber's reflections on her biases seem to highlight how her preconceptions of students inform her perception of them. In fact, three out of four of her responses reference students' familial context - which she uses to inform her interpretation of a said student's actions. Whether her assessments are right or wrong, her assertions, overall, stem from her wanting to implement behavioral interventions for 
these students - not academic. Therefore, a revised IBRT could prompt for concrete next steps.

\section{Teachers' Personal and Teaching Experiences Mediate Use of Tool}

There were similarities in themes across the case study teachers, but also significant differences in focus. Each participants' focus remained fairly consistent across their reflections, indicating that the tool did not cause them to notice different types of student actions or interactions over time (with an acknowledged limitation to this assertion being the 8-week period of the study). Therefore, the tool was effective in getting the teachers to realize that bias did play a role in their interactions, and sharpened their ability to see within their lens, but the tool did not change their lens or what it was that they were willing to look at.

For example, Amber noticed that reflecting on a student(s) who "stood out" to her, based on their learning/behavior, as well as focusing on why they stood out, was a beneficial practice for her. Therefore, a lot of her observations centered on the students she called on the most and the fact that there were a lot of differences between the boys and girls, in terms of who she noticed and addressed. In addition, she was the only participant who regularly brought up issues of race in considering how bias might play a role in her interpretations. As discussed above, Amber's reflections on race were most developed in regard to children with whom she shared racial identity. Nonetheless, she consistently mentioned the race of her students in her reflections, at least indirectly indicating that she considered race to be a potential area of bias. 
Susan, on the other hand, knew that she wanted to be conscious of her biases during the planning and execution of her lessons, but there is no evidence in the data that she did change her practice based on potential bias. Instead, her focus on appropriate behavior/ motivation impacted what she noticed and what she reflected upon. For example, out of the three participants, Susan is one who mentions race, from a "Model Minority" lens, but not correlating her views with her potentially biased action. Because she identifies as Asian American, she admits to having certain opinions for how Asian students should behave. Although she admits to asking herself introspective questions that help her to reflect upon her actions, her questions stem from what she deems to be their learning "barriers" or "categories". As a result, a lot of Susan's reflections stemmed from the lens of examining her own predispositions towards students.

Lastly, Anna sought to explore the effect of reading culturally authentic literature on a student's self-esteem. She wanted to better understand how and if students seeing their cultural representation in literature determined how they viewed themselves. Through her exploration of building awareness around how students do/don't see themselves in the literature, she realized that she may have incorporated a lot of bias into the analysis of her data. As a result, a lot of Anna's reflections centered around students she thought she was engaging, through what she perceived to be culturally relevant literature.

The developments are not necessarily a weakness of the tool, but something to be acknowledged in developing a larger-scale professional learning approach. Teachers need 
a wide variety of entry points depending on their current awareness of bias in their practice. Although the tool challenged what they were willing to look at and, "moved the needle" for acknowledging bias, there is limited evidence that the teachers took up race a large factor in bias - in a meaningful way.

\section{Limitations of Study}

Although this tool shows promise in being effective towards getting people to recognize that bias may play a role in their practice, there are still several limitations of this study. As mentioned in Chapter 4, the dichotomy of Susan's awareness of her assumptions and her limited (reported) actions to counteract these indicates that while she is aware of her biases, she is not yet able to directly apply this awareness to changes in practice. Anna is also an example of this. The results of her data do not appear to chronicle many of the supports implemented and her reflections only seem to note what she could not "assume" moving forward. She does not mention any changes that she would make to instructional content or her personal interactions, making it difficult to determine how she might make changes to her teaching practice moving forward.

One of the many reasons that I created a tool that can help teachers to notice and address implicit bias in their teaching practice is because, while the IAT helps its audience to gain a better understanding of how implicit bias is evident in specific interactions, its use does not directly connect implicit bias to practices such as those in classroom settings (Gullo, Capatosto \& Staats, 2019). Similarly, the results of the IBRT prove to be comparable. Therefore, acknowledging bias, without changes in practice 
might defeat the purpose of utilizing a tool such as the IBRT. Or, it might just mean that this tool lays the foundation for a launch into this work.

Another limitation of this study is that it was a small-scale case study, giving indepth information about three teachers, all of whom teach in the same geographic area. Additionally, each of the teachers had significant support from myself, as the researcher, to use the IBRT. Lastly, each of the participants were volunteers who willingly acknowledged that they have biases and wanted to look at their practices more deeply. Further studies should include larger-scale use of the IBRT with a wider range of teachers, as well as the identification of ideal and minimal levels of support needed from the "organizer" to produce the most benefit.

\section{Recommendations for Action}

This case study is the first step in the process of re-thinking how professional learning can support teachers to identify and act to reduce the harmful impacts of potential bias on practice. Therefore, there are several recommendations for action that I have identified as the creator and facilitator of this study.

\section{Revision of IBRT to Support Action Based on Identified Biases}

The first step in anti-bias remediation is to acknowledge that one holds biases in the first place. Without the acknowledgment, it may be difficult to springboard interventions that lead to more equitable classroom practices. Even with the results from the three participants in this study, it was apparent that the IBRT sharpened their ability to see within their own, unique lens, but their lens did not change. In order to lead to 
more substantive change, it might be useful for the teachers to participate by using the IBRT and then have a Coach to give them feedback on what they saw and have a conversation on how the results from the IBRT compares and contrasts with the observer's feedback. In this way, the conversation might push the thinking of the teacher and, potentially, lead to a generative change in practice. I suggest a coach because it is not likely that a Coach will oversee evaluating the teacher. If there is more of a mentoring relationship, then it might be easier for the teacher to participate in the conversation more openly.

Additionally, the tool could ask for the teacher to list 2 or 3 next steps that the teacher can take, based on their listed biases, to improve practice with the identified student. When the Coach meets with the teacher and reviews the results, the Coach can help the teacher to translate those action steps into modifications in practice. So, essentially, this tool meets the push for critical self-reflection, but the addition of a Coach might aide the teacher in identifying how the reflection can lead to changes in practice, based on the teacher's unique responses.

\section{Development of Full Professional Learning Approach Using IBRT}

The participants' focus on "desired behaviors" did not tend to be named by teachers as potentially biased, but instead seemed to be assumed as obvious. Professional learning for teachers around different cultural norms for behaviors and specific interventions to challenge teachers' assumptions about the reasons for children's seemingly disruptive behavior may be needed to move from bias awareness to anti-bias 
teaching - Susan and Amber both have examples of this. As stated in Chapter 2, infractions described as disruptive or disrespectful are ambiguous. Therefore, as previously noted, when something is subjective, it can lead to interpretations that are formed based on unconscious associations that are shaped by teachers' prior experiences (Staats, 2016). Often, the culture of power that many teachers develop means that they determine what appropriate behavior is and any student who acts to the contrary has something wrong with them, instead of it being considered that there might be something wrong with the teaching environment. Therefore, a full professional learning approach on the use of the IBRT would be helpful in producing more "rich" data. Additionally, the participants do not yet tie potential bias to academic outcomes. Future development of a full professional learning model around the IBRT might include work to help teachers understand the academic impact of biased disciplinary practices and expectations.

Further, as stated in Chapter 2, because implicit associations are often held outside of conscious thought, even those with egalitarian beliefs can still act in a way that produces inequitable outcomes for different groups (Staats, 2016). There is evidence that shows that implicit biases are often activated by a person's race and/ or ethnicity and are held by everyone, regardless of their race or ethnicity (Staats, 2016). Similarly, as seen in the data generated through Susan's responses, "near bias" (close to what one may have themselves experienced) may be easier for teachers to notice/name than bias that falls outside their own experience. Thus, one way that future professional learning will need to build on lessons learned from the IBRT may be to support teachers to better understand 
their students' experiences, especially those who are demographically dissimilar from themselves.

\section{Dissemination and Educational Leadership: Classroom, School, and System}

As stated in Chapter 2, an important element of transformative leadership, as defined by Shields (2010), is the deconstruction and reconstruction of frameworks that generate inequity. Transformative leadership has the power to raise human consciousness in a way that builds meaning and addresses both implicit and explicit behavior that stems from dominant cultures and structures (Shields, 2010). When a transformative leader can create a space for advocacy in response to morally guiding principles, then that is when we can begin to see change.

On a classroom level, teachers should be required to engage in bias reflection, as focused development, in their non-evaluation year. At minimum, teachers should be required to work alongside a Coach to engage in an interactive reflection process, during their non-evaluation cycle. For example, if teachers are evaluated every other year, then during their "off" year, they should have to engage in bias reflection. Developing teachers' practice is no easy feat; therefore, requiring that they have to engage in a reflective process during a time where they are trying to improve their practice might be off-putting. Although I believe that anti-bias reflection should be incorporated into their teaching practice, having the capacity to focus solely on how their biases are showing up would likely lead to the concerted attention that this topic needs. This recommendation is 
not to imply that anti-bias teaching is a stand-alone process, rather it needs focused attention to help adults to unlearn some of their potentially harmful practices.

Completing the anti-bias reflection during the evaluation process could also be viewed as punitive and should not be incorporated with a rating. Allowing teachers to reflect in a non-threatening way might produce more buy-in. Additionally, the evaluating Administrator should not be leading these reflections because, in order to get more authentic results, teachers need to feel like they are in reflecting in a non-threatening way.

On a school-level, the Coaches should create and lead an anti-bias PD at least quarterly, using anonymous results/data from the school community as a whole. Using real data allows the PD to be tailored to the specific school community and aligned to the goals and academic data of the school. These PDs should be held with groups of no more than 10 at a time, so that teachers/staff can reflect in a non-threatening way. For schools that are larger, there needs to be more Coaches so that the work is sustainable. These Coaches should have to meet at least once/month to calibrate their findings as a team and plan for their 1:1 coaching sessions and school-wide PDs.

As such, the larger system would need to make changes in order to better support and reward the kind of reflection practice reflected above. Some ideas of support could be to create compensated time for reflective practice communities; publicize or otherwise incentivize school-wide anti-bias efforts; make anti-bias coaching part of new teacher induction, with (paid) leadership opportunities for teachers who have deepened their work in this way, etc. The failure of systems to create structures of support that promote 
bias introspection means that thousands of students continue to succumb to the unrefined thoughts, views and opinions of the adults who teach them.

One thing to consider, however, is that buy-in for addressing bias from the larger education community does not necessarily mean that there will not be pushback in the methods for addressing bias. Therefore, I would expound on the idea of asking for Districts to volunteer to be part of a pilot study that would allow me to collect more authentic data and further revise the tool, based on that data. Districts that volunteer would likely be more open to looking at their biases in a non-threatening way. Because pacing matters, going too fast could limit the quality of the anti-bias implementation work. Going too slow could cause participants to push the work off to the side. Therefore, after creating an intentional timeline, based on the unique needs and results from each District, they can decide whether they want to continue to look at their teachers' biases through the implementation of the next phases of the IBRT protocol. If the District is seeing the benefits of using the tool with their teachers, they can engage in a contract that takes them to the next phases of the study - phases that would be determined based on the data collected in the pilot.

\section{Conclusion}

The results of this study support the theoretical underpinnings of the Transformative Learning Theory, which explains that critical self-reflection is an essential component that adult learners need for change. Each of the participants in this study demonstrated a willingness to reflect on their understandings in a way that allowed 
them to participate in this study from a lens of introspection and self-analysis. In other words, the explanation for how these participants' cultural and psychological assumptions drove their perceptions of students is a basic function of the Transformative Learning Theory (Biasin, 2018). Additionally, critical self-reflection is a basic component of an andragogic orientation. Participatory learning, which is what the teachers engaged in through this study, helped them to become aware of the alternate perspectives that can influence their perspective of students.

Although there are several studies that speak to the nature of implicit bias, this study sought to understand the potential impact that a tool, the IBRT, could have on a teacher's awareness of their biases and their ability to make productive changes based on this awareness. It was effective in highlighting that not only does bias exist, but that critical self-reflection is an essential component towards considering change. As I look to continue to lead work around the awareness of implicit bias, I will integrate the findings of this study towards ongoing research that supports the progressive development of education policy centered on improving the school experience of the children we serve.

As stated, the student body of the schools in my neighborhood, during my childhood, was predominantly black and lower-class, with many of the teachers that taught in the neighborhood being white. Unfortunately, school systems continue to reflect this mismatch, and the challenge caused by implicit bias has not been sufficiently acknowledged or addressed in professional learning for teachers at the individual or systemic level. Although the research literature does contend that the demographic 
mismatch of teachers to their students does tend to play a role in student outcomes, it is my hope that the iterative development of the IBRT can be used to transcend inequities that exist due to any current limiting factors. It is the responsibility of the staff of the institutions that we serve to not only name unjust perceptions, but act on changing those unjust perceptions. Therefore, I am hopeful that the IBRT not only aids one in naming their preconceptions, but that iterative versions of this same tool will lead to the positive change of practitioners world-wide. 


\section{References}

Amodio, D. M., \& Devine, P. G. (2006). Stereotyping and evaluation in implicit race bias: Evidence for independent constructs and unique effects on behavior. Journal of Personality and Social Psychology,91(4), 652-661. doi:10.1037/00223514.91.4.652

Arkes, H. R., \& Tetlock, P. E. (2004). Attributions of Implicit Prejudice, or "Would Jesse Jackson Fail the Implicit Association Test?" Psychological Inquiry, 15(4), 279-310. doi:10.1207/s15327965pli1504_02

Averett, C., Kastberg, D. (2007). The nation's report card: america's high school graduates (NCES 2007-467). U.S. Department of Education, National Center for Education Statistics. Washington, D.C.: U.S.Government Printing Office.

Bartlett, T. (1/27/2017). Can We Really Measure Implicit Bias? Maybe Not. Chronicle of Higher Education, 63(21).

Biasin, C. (2018). Transformative Learning: evolutions of the adult learning theory. Phronesis, vol. 7(3), 5-17. doi:10.3917/phron.073.0005.

Blad, E. (2017). Teachers' Cues, Subtle or Not, Shape Students' Experiences. Education Week, 36(36), 9. Retrieved from

http://search.ebscohost.com.jpllnet.sfsu.edu/login.aspx?direct=true\&AuthType=ip,cooki e,url,uid\&db=a9h\&AN=123964331\&site=ehost-live Boser, U., Wilhelm, M., \& Hanna, R. (2014). The pygmalion effect.. (n.d.) > The Free 
Library. (2014). Retrieved Mar 022018 from

https://www.thefreelibrary.com/The+Pygmalion+Effect.-a0161806846

Bowles, S., \& Levin, H.M. (1968). The determinants of scholastic achievement An appraisal of some recent evidence. The Journal of Human Resources, 3 (1), 324.

Byrk, A. (2016). Accelerating how we learn to improve. Educational Researcher, 44(9), 467-477.

Cate, I. M., Krolak-Schwerdt, S., \& Glock, S. (2015). Accuracy of teachers' tracking decisions: Short- and long-term effects of accountability. European Journal of Psychology of Education, 31(2), 225-243. doi:10.1007/s10212-015-0259-4

Charmaz, K. (2014). Constructing Grounded Theory (2nd ed.). Los Angeles: SAGE.

Çimer, A., Sabiha Odabaşi Çimer, S. O., \& Vekli, G. S. (2013). How Does Reflection Help

Teachers to Become Effective Teachers? International Journal of Educational Research, $1,133-149$.

Darling-Hammond, L. (2010). The flat world and education: how america's commitment to equity will determine our future. New York, NY: Teachers College, Columbia University.

Davis, A., Mirick, R., \& McQueen, B. (2015). Teaching From Privilege: Reflections From White Female Instructors. Affilia, 30(3), 302-313.

https://doi.org/10.1177/0886109914560742 
Day, C. (1999a). Developing Teachers: The Challenges of Lifelong Learning. London, Falmer Press.

Durksen, T. L., Klassen, R. M., \& Daniels, L. M. (2017). Motivation and collaboration: The keys to a developmental framework for teachers' professional learning. Teaching and Teacher Education,67, 53-66. doi:10.1016/j.tate.2017.05.011

Ennis, M. \& Quijano, A. (2000). Coloniality of power, eurocentrism, and latin america. Duke University Press.

Ferguson, R. (2003). Teachers' perceptions and expectations and the black-white test score gap. Urban Education. 38.

Friedrich, A., Flunger, B., Nagengast, B., Jonkmann, K., \& Trautwein, U. (2015). Pygmalion effects in the classroom: Teacher expectancy effects on students math achievement. Contemporary Educational Psychology,41, 1-12. doi:10.1016/j.cedpsych.2014.10.006

Georgetown University Center on Education and the Workforce. (2019, May 15). Born to Win, schooled to lose: Why equally talented students don't get equal chances to be all they can be. Retrieved from https://cew.georgetown.edu/

Gershenson, S., Holt, S., \& Papageorge, N. (2015). Who believes in me? The effect of student-teacher demographic match on teacher expectations. SSRN Electronic Journal. doi:10.2139/ssrn.2633993

Good, T. L. (1987). Two Decades of Research on Teacher Expectations: Findings and 
Future Directions. Journal of Teacher Education,38(4), 32-47. doi:10.1177/002248718703800406

Good, T. L., \& Brophy, J. E. (1970). Teacher-child dyadic interactions: A new method of classroom observation. Journal of School Psychology,8(2), 131-138. doi:10.1016/0022-4405(70)90032-4

Gladwell, M. (n.d). Blink: The Power of Thinking withut Thinking. Retrieved from https://www.barnesandnoble.com/w/blink-malcolm-gladwell/1100022866

Goldenberg, B. (2014). White Teachers in Urban Classrooms: Embracing Non-White Students' Cultural Capital For Better Teaching and Learning. Urban Education,111-144.

Greenwald, A. G., Nosek, B. A., \& Banaji, M. R. (2003). Understanding and using the Implicit Association Test: I. An improved scoring algorithm. Journal of Personality and Social Psychology,85(2), 197-216. doi:10.1037/0022-3514.85.2.197

Gullo, G. L., Capatosto, K., \& Staats, C. (2019). Implicit Bias in Schools. doi:10.4324/9781351019903

Jacoby-Senghor, D. S., Sinclair, S., \& Shelton, J. N. (2016). A lesson in bias: The relationship between implicit racial bias and performance in pedagogical contexts. Journal of Experimental Social Psychology,63, 50-55. doi:10.1016/j.jesp.2015.10.01

Jussim, L., Eccles, J., \& Madon, S. (1996). Social Perception, Social Stereotypes, and 
Teacher Expectations: Accuracy and the Quest for the Powerful Self-Fulfilling Prophecy. Advances in Experimental Social Psychology Advances in Experimental Social Psychology Volume 28,281-388. doi:10.1016/s00652601(08)60240-3

Mezirow, J. Contemporary paradigms of learning. Adult education quarterly, 1996. 46, $158-172$.

Mezirow, J. (1997). Transformative Learning: Theory to Practice. New Directions for Adult and Continuing Education, 1997(74), 5-12. doi: 10.1002/ace.7401

Moore-Johnson, S. \& Simon, N. (2015). Teachers College Record Volume 117 Number 3, 2015, p. 1-36. http://www.tcrecord.org/library ID Number: 17810, Date Accessed: 3/2/201812:42:33 AM

Oakland Unified School District. Fast Facts. 2018-2019. Oakland, CA

Oakland Unified School District. Reading Inventory Student Performance. 20172018. Oakland, CA

Oakland Unified School District. Teacher Data Snapshot. 2018-2019. Oakland, CA Peterson, E., Rubie-Davies, C., Osborne, D., \& Sibley, C. (2016). Teachers explicit expectations and implicit prejudiced attitudes to educational achievement: Relations with student achievement and the ethnic achievement gap. Learning and Instruction,42, 123-140. doi:10.1016/j.learninstruc.2016.01.010

Rist, R. C. (2000) Student social class and teacher expectations: The self-fulfilling prophecy in ghetto education. Harvard Edcuational Review. 
Rosenthal, R., \& Jacobson, L. (1968). Pygmalion in the classroom: teacher expectation and pupils' intellectual development. New York: Holt, Rinehart and Winston.

Shields, C. M. (2010). Transformative Leadership: Working for Equity in Diverse Contexts. Educational Administration Quarterly,46(4), 558-589. doi:10.1177/0013161×10375609

Shields, C. M. (2010). Transformative Leadership: Working for Equity in Diverse Contexts. Educational Administration Quarterly, 46, 558-589.

Skiba, R., Michael, R., A.C., N., \& R.L., P. (2002). The color of discipline: Sources of racial and gender disproportionality in school punishment. The Urban Review.

Staats, C. (2016). Understanding implicit bias: What educators should know. The American Educator.

Steele, C. (1997). A threat in the air: how stereotypes shape intellectual identity and performance. The American psychologist. 52. 613-29. 10.1037/0003-

066X.52.6.613.

Steele, D. M., \& Cohn-Vargas, B. (2013). Identity safe classrooms: places to belong and learn.Thousand Oaks, CA: Corwin, a Sage Company.

Stevens, C., Liu, C. H., \& Chen, J. A. (2018). Racial/ethnic disparities in US college students' experience: Discrimination as an impediment to academic performance. Journal of American 
College Health, 66(7), 665-673. https://doi-

org.jpllnet.sfsu.edu/10.1080/07448481.2018.1452745

Taylor, E. (2008). Transformative learning theory. Wiley interscience.

10.1002/ace.301

University of Vermont. (2015, July 15). Color-blind? Whites aware of their bias better equipped for modern race issues, says new study. ScienceDaily. Retrieved April 12, 2019 from www.sciencedaily.com/releases/2015/07/150715103510.htm

Gates, G. S., \& Watkins, M. (2010). The Place of Autonomy in School Community: Taking a Closer Look at Teacher Collaboration. Journal of School Leadership, 20(3), 272-303. https://doi.org/10.1177/105268461002000302

W.E.B Du Bois and Double Consciousness. (2014, February 22). Retrieved from https://roadrunnertheory.wordpress.com/2014

Weissglass, J. (2001). Racism and the Achievement Gap. Education Week, 20(43), 72. Retrieved from http://search.ebscohost.com.jpllnet.sfsu.edu/login.aspx?direct=true\&AuthType=ip ,cookie,url,uid\&db=a9h\&AN=5021753\&site=ehost-live

Wright, R. (2016). Race Matters and So Does Gender.

Yosso, T. (2005) Whose culture has capital? A critical race theory discussion of community cultural wealth, Race Ethnicity and Education, 8:1

Yosso, T., Smith, W., Ceja, M., \& Solórzano, D. (2009). Critical Race Theory, 
Racial Microaggressions, and Campus Racial Climate for Latina/o Undergraduates. Harvard Educational Review, 79(4), 659-69 


\section{Appendix A}

\section{Interview \#1 Protocol}

- What grade do you teach?

- How long have you been a teacher?

- What was your education pathway?

- What are some practices that you engage in to improve students' academic outcomes?

- How do you define implicit bias?

- What affects, if any, has bias played in your classroom?

- What are some ways that we can become conscious of our biases during the planning and execution of lessons?

- What role might bias play in the examination and determination of teacher research questions? 


\section{Appendix B \\ Interview \#2 Protocol \\ (used in conjunction with viewing video through Equip Platform)}

- Who didn't do as you expected?

- Who struggled to stay on task?

- How were groupings determined?

- How would you describe X's performance?

- Who would your focal students be and why?

- Is there anything else that stood out? 
Appendix C

\section{IBRT \#1}

1. Which student did you notice and/or address, today?

2. What behaviors/interactions made the aforementioned student particularly noticeable?

3. How would you describe your interpretation of their behavior?

4. Describe, specifically, your interaction with said student.

5. What were the possible areas of bias in the context? Gender, race, language, class etc?

6. How did you know a moment of bias happened?

7. What contextual factors might determine how you perceive the student's actions?

8. How do you classify the student's academic performance? (i.e. what "grouping" does the student belong)?

9. Describe the student's behavioral history.

10. What about the student's behavior was particularly troublesome for you?

11. If you had to choose a student whose "behavior" was the exact opposite of this student's, how would you describe the prototypical behavior?

12. What are some adjectives/themes have come up for you as you describe this student?

13. What type of feelings come up for you as you describe this student's actions?

14. During a typical school week, how many days would you estimate you address this student's behaviors?

15. What, if anything, have you put in place to address your interactions with the student? 
16. How would you describe your desire for the student to behave?

17. From where does that desire stem?

18. If possible, insert a video clip of the student engaged in undesirable behavior.

19. What is the context surrounding the clip?

20. How do you try to build rapport, in general?

21. How have you tried to build rapport with this student?

22. What check-ins, if any, have you had with the student?

23. What strategies have you used to engage this student as a learner?

24. How do you feel when you are teaching this student?

25. What strengths does he/she bring from their home life?

26. What challenges does he/she bring from their home life?

27. What assumptions are you making about the student's behavior?

28. How can you respond differently?

29. What does your bias teach you about your student?

30. How might your bias keep you from seeing what your student might need from you? 


\section{Appendix D}

\section{Final IBRT}

1. Choose one student who you particularly noticed today, and whose learning/behavior you would like to reflect upon. List their name, below.

2. Write a narrative around what behavior/interaction(s) made this student particularly noticeable. Write about their "story", today.

3. Describe, specifically, what the student said or did. Provide at least 3-4 concrete examples.

4. What does their "story", described in the prior section, assume about the student?

5. If any part of the student's behavior seemed problematic to you, describe the preferred behavior.

6. Find one way in which bias might be informing your interpretation? Consider the student's race, class, gender, language, etc.

7. Based on the analysis you have just done, in questions $3-6$, what is one thing that you could do differently? 
Appendix E

\section{First Reflection on IBRT}

- What worked well?

- What was difficult?

- How can the tool can be improved?

- Can you send me a copy of your field study syllabus?

- How, if any, do you see this data fitting into your field study?

- Where do you see me fitting in with supporting you in your field study? 


\section{Appendix F}

\section{Final Reflection on IBRT}

- In what ways did you find using the IBRT helpful?

- Do you feel it helped you notice implicit bias and make appropriate changes?

- What do you plan to do moving forward to continue to build awareness of bias and address the issues that arise? 